\title{
Soil Mapping, Monitoring, and Assessment
}

\author{
Mark J. Kimsey, Larry E. Laing, Sarah M. Anderson, \\ Jeff Bruggink, Steve Campbell, David Diamond, \\ Grant M. Domke, James Gries, Scott M. Holub, \\ Gregory Nowacki, Deborah S. Page-Dumroese, \\ Charles H. (Hobie) Perry, Lindsey E. Rustad, \\ Kyle Stephens, and Robert Vaughan
}

\section{Introduction}

Soils are a nonrenewable resource that support a wide array of ecosystem functions. The scope of these functions depends on the nature and properties of the soil at a given location on the Earth. Demand for better soil information has been growing since the development of soil science in the nineteenth century. This recent interest is driven by an increasing recognition of the ecological, economic, and societal benefits of understanding soil properties and the value of that knowledge for realizing management objectives for agriculture, grazing, forestry, and other land uses. Soil surveys are one method for amassing soil data and mapping the extent of various soil types. The Federal Government has singularly been a long-term sponsor of soil

M. J. Kimsey $(\bowtie)$

College of Natural Resources, University of Idaho,

Moscow, ID, USA

e-mail: kimsey@uidaho.edu

L. E. Laing

U.S. Department of Agriculture, Forest Service, Forest

Management, Range Management, and Vegetation Ecology,

Washington, DC, USA

S. M. Anderson

U.S. Department of Agriculture, Forest Service, Forest

Management, Range Management, and Vegetation Ecology,

Washington, DC, USA

J. Bruggink

U.S. Department of Agriculture, Forest Service, Intermountain

Region, Ogden, UT, USA

S. Campbell

U.S. Department of Agriculture, Natural Resources Conservation

Service, West National Center, Portland, OR, USA

D. Diamond

Greater Yellowstone Coordinating Committee,

Bozeman, MT, USA

G. M. Domke · C. H. (Hobie) Perry

U.S. Department of Agriculture, Forest Service, Northern Research

Station, St. Paul, MN, USA surveys in the United States. The history of these surveys is richly documented and illustrated by Helms et al. (2008). Soil surveys describe horizontal (e.g., soil series) and vertical (e.g., horizon depth) properties of soils. Soil mapping enhances assessments of spatial variability in the development and properties of soils as a function of geology, climate, topography, and vegetation. Extensive sampling of soils in concert with other attributes (e.g., forest or rangeland composition) can provide focused estimates and understanding of the linkages between soils and vegetation growth, mortality, and C stocks (O'Neill et al. 2005) (Box 9.1). Thus, soils are not independent of biogeophysical settings and climate, but rather are a result of these variables. Management interpretations of soil functions and processes such as erosion, potential vegetation growth, and

J. Gries

U.S. Department of Agriculture, Forest Service, Eastern Region, Milwaukee, WI, USA

S. M. Holub

Weyerhaeuser, Springfield, OR, USA

G. Nowacki

U.S. Department of Agriculture, Forest Service, Eastern Region, Milwaukee, WI, USA

D. S. Page-Dumroese

Rocky Mountain Research Station, USDA Forest Service, Moscow, ID, USA

L. E. Rustad

U.S. Department of Agriculture, Forest Service, Northern Research Station, Center for Research on Ecosystem Change,

Durham, NH, USA

K. Stephens

U.S. Department of Agriculture, Natural Resources Conservation Service, Portland, OR, USA

R. Vaughan

U.S. Department of Agriculture, Forest Service, Geospatial Technology Applications Center,

Salt Lake City, UT, USA 


\section{Box 9.1 Case Study}

Use of Soil Maps for Vegetation Classification and Management in the Southern United States.

The relationship of soils to potential vegetation is a key element in the use of soil maps to develop current vegetation maps. The USDA Natural Resources Conservation Service (USDA NRCS) defines ecological sites as geophysical settings that support similar plant communities under similar management and disturbance regimes, and each ecological site type is unique (see USDA NRCS 2012). In that regard, they are similar to ecological site type and site type phase concepts used by the USDA Forest Service in its hierarchal classification of ecoregions, land types, and site types (ECOMAP 1993).

Statewide digital soil maps served as key input data for mapping ecological systems at relatively fine resolution in Texas and Oklahoma, and similar efforts are underway for Kansas and Nebraska (Diamond and Elliott 2015). Ecological systems represent individual or groups of colocated plant communities (see NatureServe 2019).

In Texas and Oklahoma, digital Soil Survey Geographic (SSURGO) datasets were intersected with land cover from satellite remote sensing to produce relatively fineresolution (10 m) current vegetation maps (Box Fig. 9.1). Groups of similar ecological site types, informed by site type descriptions (see USDA NRCS n.d.), were used to infer current vegetation (Box Fig. 9.2). The location and extent of ruderal and invasive vegetation types were inferred based on the soil maps. For example, evergreen forest and woodland land cover on prairie soils were classified as "Ruderal Eastern Redcedar Woodland and Forest" (Box Fig. 9.3).

For the national forests and grasslands in Texas, additional information on the plant communities as related to soils and landforms was available, and these data were used to map ecological land types and land type phases (Box Fig. 9.4) (Diamond and Elliott 2010; Van Kley et al. 2007). These maps have been improved and modified and serve as guides to forest management and planning. For example, the location of potential longleaf pine (Pinus palustris) restoration areas was mapped (Box Fig. 9.5).

The key element enabling use of soil maps for vegetation mapping and definition of management alternatives is explicitly relating soils to ecological site or ecological land type concepts. Management actions (e.g., timber harvesting, grazing) will have different impacts on the same plant community when it occurs over different soils and ecological sites. Hence, replanting of longleaf pine in southeastern Texas is most likely to be successful on soils and in geophysical settings that once supported

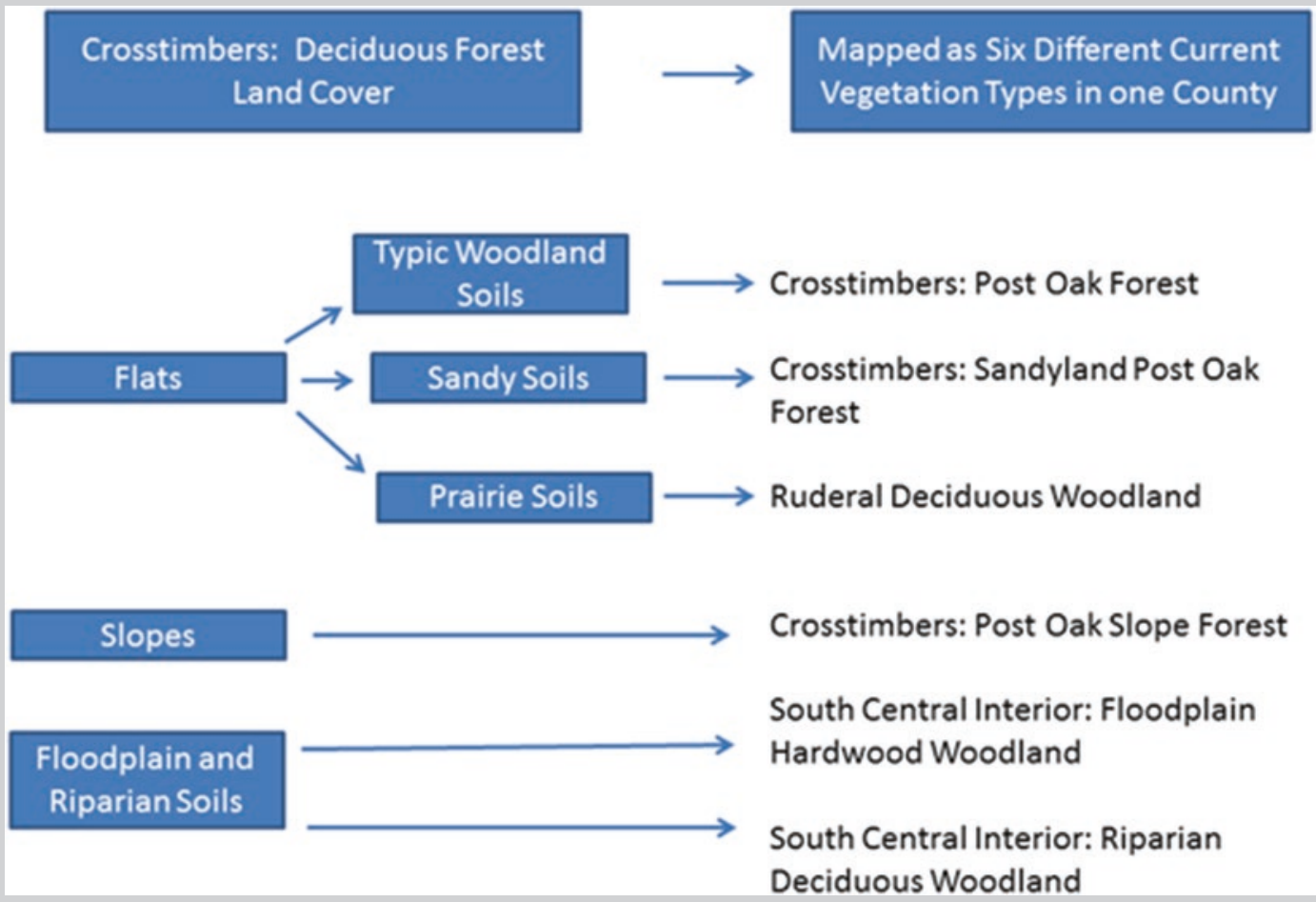

Box Fig. 9.1 Six different deciduous forest ecological system types were mapped for the Crosstimbers in Texas and Oklahoma based on differences in soils and percent slope. (Source: Soil data from NRCS SSURGO maps; land cover from satellite remote sensing) 
Box 9.1 (continued)

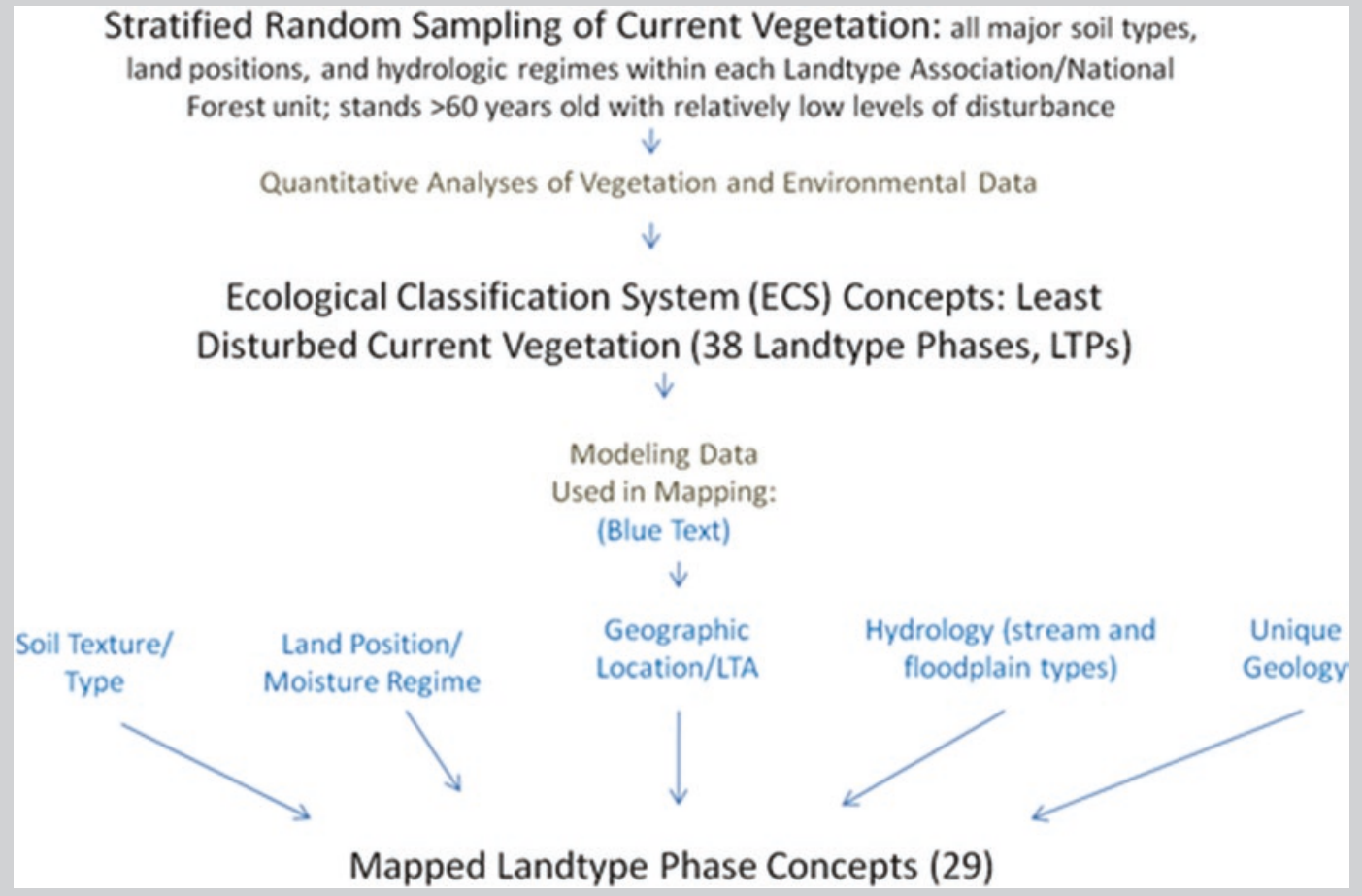

Box Fig. 9.2 Outline of the development of Ecological Classification System (ECS) land type phase (LTP) concepts and modeling data used for mapping these concepts. Soil maps are a key component in this process

Box Fig. 9.3 Ruderal (invasive) deciduous community types (shown in green) and eastern redcedar (Juniperus virginiana) community types (shown in red) were mapped in Payne County, Oklahoma, by referencing ecological site descriptions of the historic vegetation as documented in the Soil Survey Geographic (SSURGO) dataset. Urban land cover in Stillwater, OK, (upper left) and Cushing, OK, (lower right) are shown in gray

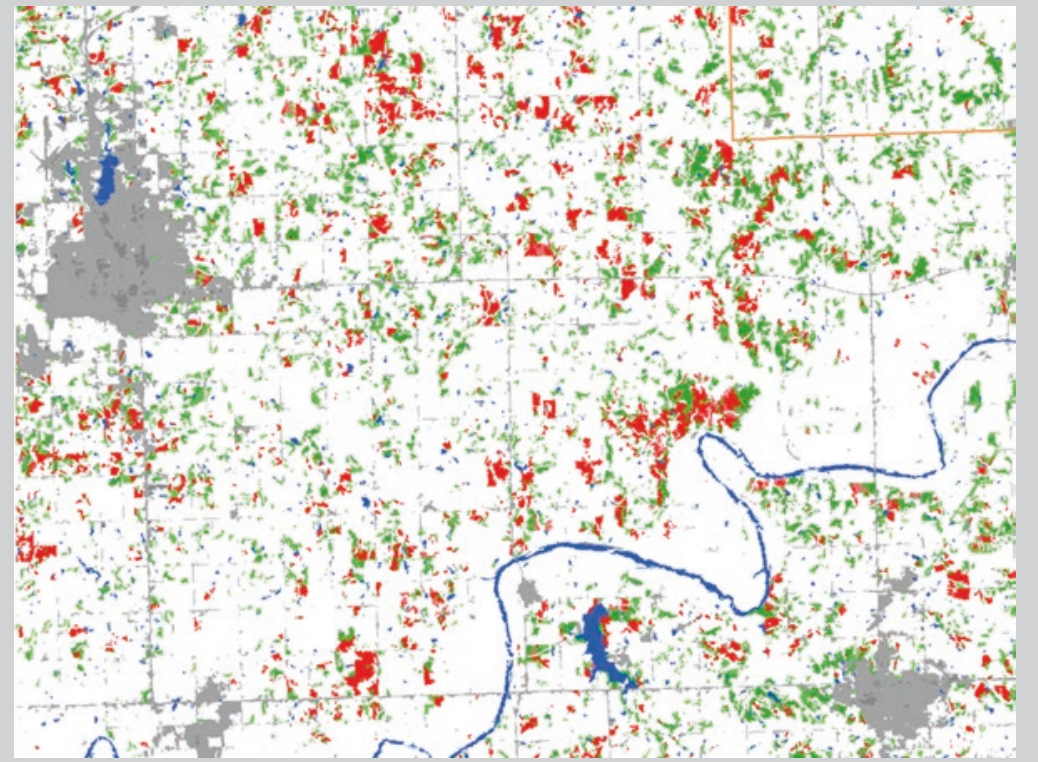

longleaf pine communities. Harvesting and planting of any given tree species on sands versus clays, or on steep slopes versus flats, may result in different future timber volume, or possibly even in different plant community types, decades later. Management of soils can thus be viewed as inseparable from management of plant communities, and knowledge of the soils (ecological sites) will inform appropriate management options and expectations. 
Box 9.1 (continued)

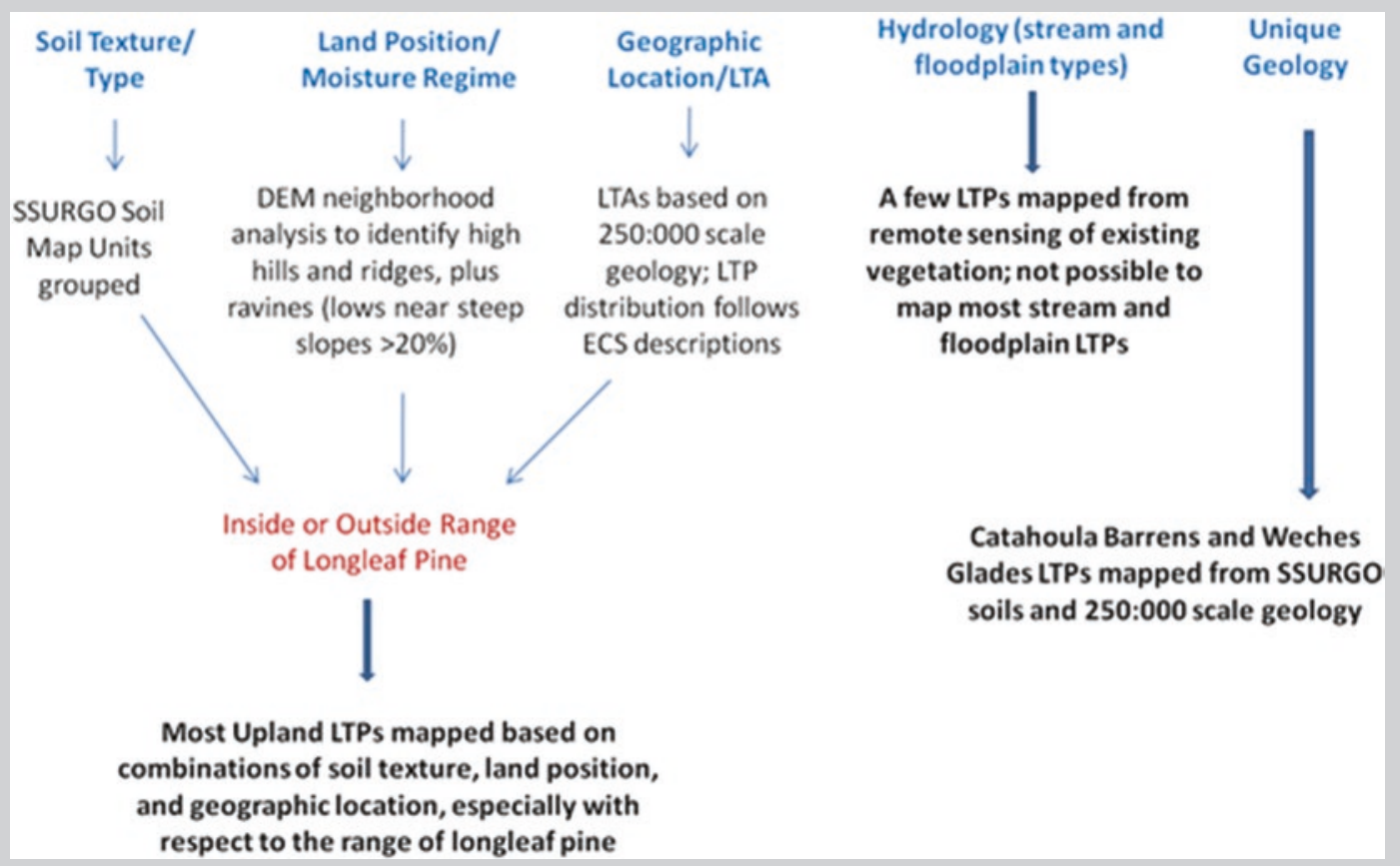

Box Fig. 9.4 Primary data layers used for modeling and mapping of Ecological Classification System (ECS) land type phase (LTP) concepts. Twenty-nine of 38 LTP concept types defined from field sampling were mapped. (SSURGO=Soil Survey Geographic database; $\mathrm{DEM}=$ digital elevation model)

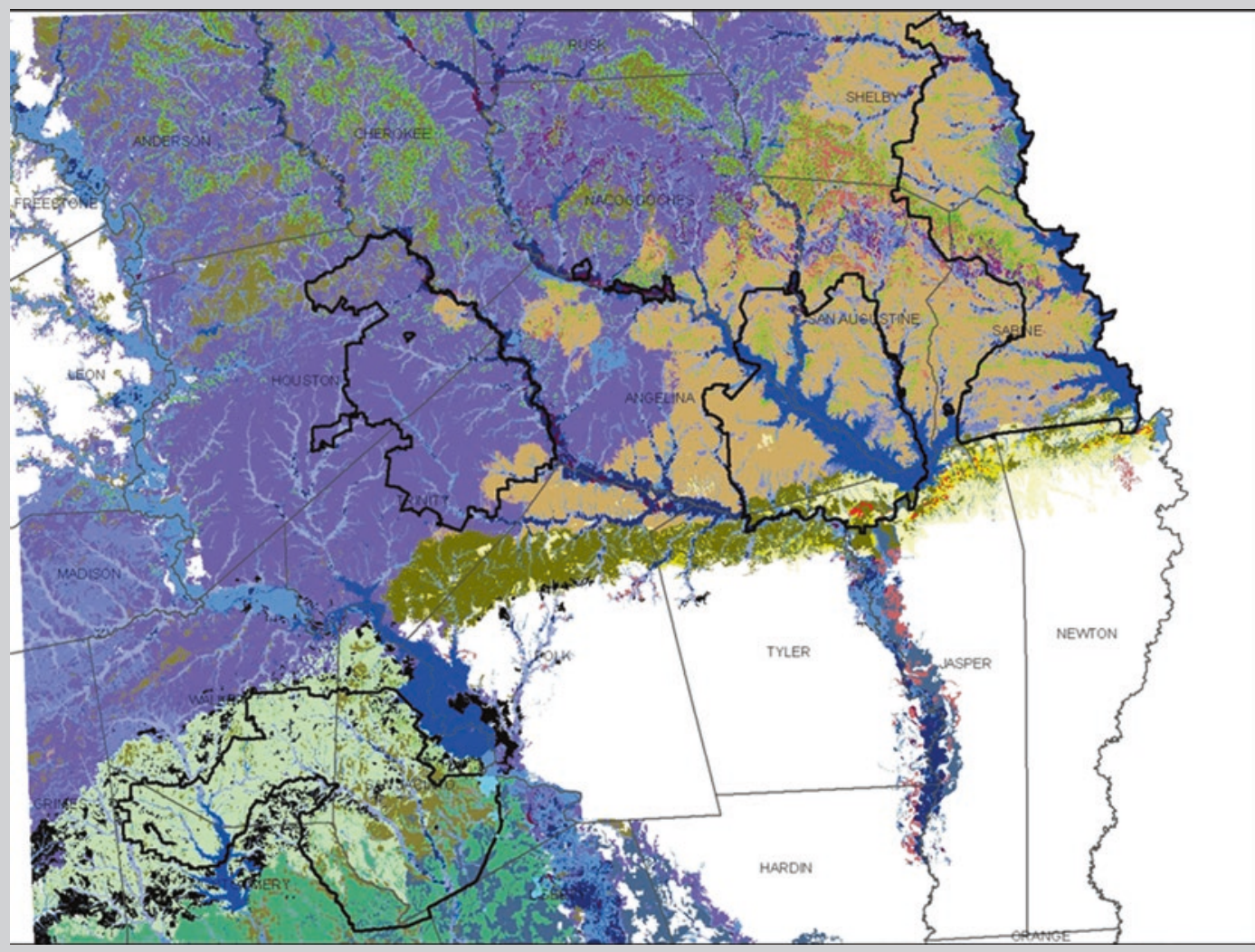

Box Fig. 9.5 Ecological land types for the area surrounding four National Forest Units in southeastern Texas (black outlines). Each color represents a unique ecological site type based on soils and landforms. For example, tan, yellow, and olive colors indicate site types where longleaf pine (Pinus palustris) communities historically occurred, and indicate potential locations where this community type could be restored 
hydrologic function integrate these factors and offer an index for land use limitations and opportunities.

In early soil mapping efforts, flat paper maps were produced by taking information from field surveys and combining it with information from aerial imagery obtained through the use of stereoscopes. Later, these maps have been georeferenced and converted to digital data products. Modern techniques involve more accurate georeferencing, use of digital elevation models from remote sensing or ground measurements, and inclusion of vegetation maps, which help provide more detailed mapping at a variety of scales.

Initially, soil survey efforts in the United States focused on farmlands where the need to understand and manage soils in association with crop production was most keen. Over time, Federal- and state-managed forests and rangelands were mapped. These latter efforts placed greater emphasis on plant communities as they relate to landscape position and soil characteristics, and fine-resolution units were grouped within spatially nested hierarchies (Schoeneberger et al. 2012). Early soil mapping was typically conducted at the scale of 1:24,000 (e.g., 1 map $\mathrm{cm}=24,000$ ground $\mathrm{cm}$ ), although some wildlands were mapped at coarser scales (e.g., 1:63,360). Soil surveys are now generally available online and can be accessed through portals such as Web Soil Survey (https://websoilsurvey.sc.egov.usda.gov/), a Webbased soil property mapping program developed by the US Department of Agriculture's Natural Resources Conservation Service (USDA NRCS).

The USDA NRCS and the USDA Forest Service (hereafter, Forest Service) use different multi-scale approaches to capture and provide context to soil information. Each agency has spatially nested, multi-resolution mapping systems, but these are not uniformly complete across the United States. The USDA NRCS products most often focus on soil, whereas the Forest Service explicitly considers soils and vegetation together as an integrated unit for mapping (e.g., Terrestrial Ecological Unit Inventory (TEUI); https://www.fs.fed.us/ soils/teui.shtml). Both agencies are moving toward more integrated products that capitalize on an ecological, spatially nested, and multi-resolution context as mapping priorities move toward an all-lands context (see Box 9.2). Variations, where they occur, relate to differing policy and management needs between the two agencies.

In the future, soil mapping will likely be integrated with additional ecological variables and will place a greater emphasis on predicting soil responses to climate change and subsequent implications for agriculture, rangeland and forest management, wetlands, and many associated ecological services. Soils and their associated site characteristics will be used to predict changes in moisture balance and temperature, including the potential responses of vegetation communities to changing climates. Greater use will be made of the various scales of soil-related information. For example, land type associations (see Chap. 8) are used in forest planning to group finer-resolution, integrated soil and vegetation units and provide ecological context to assess ecological integrity and frame desired conditions for management. In turn, the coarser-scale groupings of soil and associated data can be used to support larger-scale planning (e.g., across national forest boundaries).

Because ecosystems are in a state of permanent flux at a variety of spatial and temporal scales, remote sensing plays a critical role in digitally detecting changes in vegetation type and cover amounts over time (Coppin et al. 2004). These data can be used to define elevation and vegetation patterns and to improve the consistency, accuracy, and precision of soil and associated ecological map products. Landform modeling with remotely sensed data can be accomplished at multiple spatial resolutions and can provide new insights at a variety of scales, which is particularly useful when assessing land use and wildfire impacts on factors such as hillslope stability. Computer hardware and software capabilities and efficiencies will continue to advance, ensuring better quality data analyses and increased accessibility to users.

When presented in an ecological context, soils help provide a baseline for future monitoring and assessment following management activities or natural perturbation. According to the Oxford Dictionary, to monitor something means to "observe and check the progress or quality of (something) over a period of time; keep under systematic review," and assessment is defined as "the evaluation or estimation of the nature, quality, or ability of something." Monitoring is the systematic observation and recording of conditions over time, whereas assessments combine monitoring data to inform decision-making and planning.

During monitoring, soil conditions are measured systematically over time to assess changes in soil properties. Sometimes these changes are direct and evident and in other cases they are inferred. For example, one of the goals of the North American Long-Term Soil Productivity (LTSP) study, a program involving the Forest Service and global partners, is to monitor the effects of a pulse change in soil compaction and organic matter removal on tree growth and health, soil recovery, and changes in ecological functions across a range of ecological settings (Ponder et al. 2012). The intent is to validate soil monitoring efforts and evaluate changes in productivity as they relate to soil disturbance, particularly those perceived as detrimental (i.e., slow recovery of soil functions). Furthermore, soil sampling undertaken by the Forest Service's Forest Inventory and Analysis (FIA) program is conducted as a "remeasurement," which facilitates change detection over time and space relative to initial site characterization data. Additional options exist to facilitate intensive 


\section{Box 9.2 Soil Inventory Products and Delivery Mechanisms}

\begin{tabular}{|c|c|}
\hline Product & Description \\
\hline $\begin{array}{l}\text { Soil Survey Geographic } \\
\text { (SSURGO) database }\end{array}$ & $\begin{array}{l}\text { The flagship product of the National Cooperative Soil Survey. Contains } \\
\text { field-validated tabular and spatial soil information collected over the last } \\
118 \text { years, compiled to a uniform digital standard. Data was developed at } \\
\text { scales ranging from } 1: 12,000 \text { to } 1: 63,360 \text { but was predominantly } \\
\text { developed at } 1: 24,000 \text {. Available for most areas in the continental United } \\
\text { States and the territories, commonwealths, and island nations served by } \\
\text { the USDA NRCS. Limited SSURGO data is available for Alaska. }\end{array}$ \\
\hline
\end{tabular}

State soil geographic (STATSGO2) database

\section{Gridded} (gSSURGO) database
Soil Survey Graphic

The National Cooperative Soil Survey (NCSS) general soil map of the United States and its Island Territories. A broad-based inventory mapped at a scale of 1:250,000 in the continental United States, Hawaii, Puerto Rico, and the Virgin Islands and at 1:1,000,000 in Alaska. The only NCSS product that delivers complete coverage of all areas of the United States and its Island Territories. Designed for broad planning and management uses covering state, regional, and multistate areas. The US general soil map is composed of general soil association units and is maintained and distributed as a spatial and tabular dataset.

A rasterized version of SSURGO delivered in the format of an Environmental Systems Research Institute, Inc. (ESRI®) file geodatabase. A file geodatabase has the capacity to store more data and greater spatial extents than the traditional SSURGO product. This makes it possible to offer these data in statewide or even conterminous United States (CONUS) tiles. The gSSURGO database contains all the original soil attribute tables found in SSURGO. All spatial data are stored within the geodatabase instead of externally as separate shapefiles.

Raster Component Maps Component-based soil inventories for a select few areas of the United States delivered as a raster product, in the same format as gSSURGO. Coverage by this relatively new product is currently limited, but is expected to increase in the coming years.

National Cooperative Soil Survey (NCSS) soil characterization database

\section{Contains soil characterization data (laboratory data) from the NCSS}

Kellogg Soil Survey Laboratory and cooperating laboratories. Data can be queried, viewed, and downloaded as comma-delimited text files. Two additional files, a NCSS Microsoft access database containing nearly all results from laboratory analysis and a corresponding ESRI@ file geodatabase containing sample locations, are also available for download.

Forest Inventory and Analysis (FIA)

\section{Soil Resource}

Inventories (SRI) and

Land System Inventories (LSI) across all ownerships. Information collected includes the area of forest land and its location; the species, size, and health of trees; and total tree growth, mortality, and removals by harvest and land use change. The Forest Service has significantly enhanced the FIA program by changing from a periodic survey to an annual survey. The scope of data collection has also expanded to include soil, understory vegetation, tree crown conditions, coarse woody debris, and lichen community indicator of air quality and climate on a subsample of plots. By increasing the capacity to analyze and publish the underlying data and information and knowledge products derived from the data, more information is now readily available.

The land systems inventories and soil resource inventories are based on 1970s and 1980s Forest Service direction to provide land base integrated inventories to meet management needs. Land system inventories are a mapping effort focused on an integrated ecological inventory based on

\begin{tabular}{|l|l|}
\hline Delivery system & Agency $^{\mathrm{a}}$ \\
\hline $\begin{array}{l}\text { Web Soil Survey } \\
\text { Soil data access } \\
\text { Geospatial gateway }\end{array}$ & NRCS \\
\hline $\begin{array}{l}\text { Web Soil Survey } \\
\text { Soil data access } \\
\text { Geospatial gateway }\end{array}$ & NRCS \\
\hline & \\
& \\
\hline
\end{tabular}

Geospatial gateway NRCS

Geospatial gateway NRCS

NCSS

NRCS

characterization

database

FIA DataMart geology, geomorphology, soils, and vegetation; most of this mapping has been centered in Idaho in the Intermountain Region. The mapping is designed to fit with the national hierarchy of ecological units. These mapping efforts are typically defined at a broad scale by geology and geomorphology and refined more locally by soils and vegetation. Some SRI completed in the Pacific northwest region describes soil characteristics and classifies the soils of a given area, maps the boundaries and spatial patterns of the soils, and makes predictions about the soil behavior. Data and descriptive information for LSI and SRI inventories are available at Forest Service regional and national forest and ranger district offices.

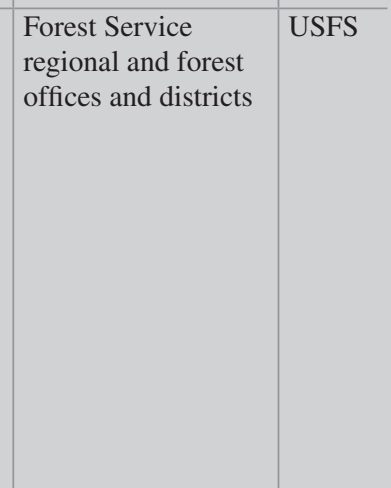


soil monitoring across the Forest Service's Experimental Forests and Rangelands system (EFR), Long-Term Ecological Research (LTER) network, NRCS Natural Resources Inventory, National Ecological Observatory Network (NEON), and the National Park Service's Inventory and Monitoring networks. In addition, national soil monitoring networks can be linked to various international soil monitoring networks for providing global context to changes observed spatially and temporally (see Box 9.3).

Assessments are designed to characterize and quantify impacts to soil related to disturbances, regardless of cause. Repeated assessments over time provide a monitoring framework to measure recovery rates. This assessment-monitoring continuum provides measures and interpretations relating to severe levels of disturbance that impair soil productivity and site sustainability in areas subjected to forest and range management activities, such as timber sale units, range allotment pastures, or fuels treatment areas. The Forest Service, Bureau of Land Management (BLM), and others have developed soil disturbance sampling guides to aid data collection and best management practices. Many assessments are at a finer scale (e.g., soil rutting by equipment) and tend to focus on specific impacts to soil properties (e.g., decreased water infiltration from soil compaction) and the ramifications that these changes have on ecosystem or agricultural services. Other assessments, such as the Forest Service's Terrestrial Condition Assessment and the Variable Width Riparian Model, ascertain conditions associated with distinct landscapes and their associated soil/vegetation patterns to aid in evaluating ecosystem health and productivity (Abood et al. 2012).

\section{Soil Mapping}

\section{Historical Context}

The effort to inventory the soils of the United States has been underway since 1899, when Dr. Milton Whitney, the first Chief of the recently formed Division of Agricultural Soil, initiated surveys on tobacco (Nicotiana tabacum) farmlands in Maryland and Connecticut. Initially, most soil surveys focused on cultivated lands because early objectives of soil mapping were to better understand chemical soil properties and their effects on crop production. Over the last 118 years, much has changed, and the objectives of the soil inventory have greatly expanded, and they now include soil and water conservation, timber production, grazing, wildlife habitat, shellfish habitat, recreation, air quality, disaster response, land use planning, and ecosystem management. Furthermore, the soil inventory is no longer the purview of the long defunct

Box 9.3 Examples of Soil Monitoring Networks

\begin{tabular}{|c|c|c|c|c|c|c|}
\hline Network name & Acronym & $\begin{array}{l}\text { Primary } \\
\text { agency }^{\mathrm{a}}\end{array}$ & $\begin{array}{l}\text { Number } \\
\text { of sites }\end{array}$ & $\begin{array}{l}\text { Year } \\
\text { established }\end{array}$ & Focus & Web address \\
\hline \multicolumn{7}{|c|}{ Comprehensive research programs } \\
\hline $\begin{array}{l}\text { Experimental Forests and } \\
\text { Rangelands }\end{array}$ & EFR & USFS & 80 & 1909 & $\begin{array}{l}\text { Forests, rangelands, and watersheds: } \\
\text { managing and restoring sites; } \\
\text { characterizing plant and animal } \\
\text { communities; observing and } \\
\text { interpreting long-term environmental } \\
\text { change }\end{array}$ & $\begin{array}{l}\text { https://www. } \\
\text { fs.fed.us/ } \\
\text { research/efr/ }\end{array}$ \\
\hline $\begin{array}{l}\text { Long Term Ecological } \\
\text { Research }\end{array}$ & LTER & NSF & 26 & 1876 & $\begin{array}{l}\text { Natural systems: studying the } \\
\text { influence of long-term and large-scale } \\
\text { phenomenon on different ecosystems }\end{array}$ & $\begin{array}{l}\text { https://lternet. } \\
\text { edu/ }\end{array}$ \\
\hline $\begin{array}{l}\text { National Ecological } \\
\text { Observatory Network }\end{array}$ & NEON & NSF & 81 & 2015 & $\begin{array}{l}\text { Natural terrestrial and aquatic } \\
\text { systems: measuring causes and effects } \\
\text { of environmental change }\end{array}$ & $\begin{array}{l}\text { http://www. } \\
\text { neonscience.org/ }\end{array}$ \\
\hline $\begin{array}{l}\text { National Critical Zone } \\
\text { Observatory Network }\end{array}$ & $\mathrm{CZO}$ & NSF & 10 & 2007 & $\begin{array}{l}\text { Natural, undisturbed systems: } \\
\text { studying how chemical, physical, and } \\
\text { biological processes interconnect }\end{array}$ & $\begin{array}{l}\text { http:// } \\
\text { criticalzone.org/ } \\
\text { national/ }\end{array}$ \\
\hline $\begin{array}{l}\text { Organization of Biological } \\
\text { Field Stations }\end{array}$ & OBFS & Various & 241 & 1963 & $\begin{array}{l}\text { Understanding natural processes at } \\
\text { every scale }\end{array}$ & $\begin{array}{l}\text { http://www.obfs. } \\
\text { org/ }\end{array}$ \\
\hline \multicolumn{7}{|c|}{ Targeted research networks } \\
\hline $\begin{array}{l}\text { Forest Inventory and } \\
\text { Analysis }\end{array}$ & FIA & USFS & $\begin{array}{l}1 \text { per } \\
6000 \\
\text { acres }\end{array}$ & 1930 & US forests & $\begin{array}{l}\text { https://www.fia. } \\
\text { fs.fed.us/ }\end{array}$ \\
\hline $\begin{array}{l}\text { Soil Climate and Analysis } \\
\text { Network }\end{array}$ & SCAN & NRCS & 219 & 1991 & Agricultural areas & $\begin{array}{l}\text { https://www.wcc. } \\
\text { nrcs.usda.gov/ } \\
\text { scan/ }\end{array}$ \\
\hline
\end{tabular}

a USFS USDA Forest Service, NSF National Science Foundation, NRCS USDA Natural Resources Conservation Service 
Division of Agricultural Soil, but instead it is the responsibility of the National Cooperative Soil Survey (NCSS), a nationwide partnership of Federal, regional, state, and local agencies, along with private entities and institutions. The Soil Science Division, a subdivision of the USDA NRCS, is the only agency charged with inventorying the soils of all lands, and as a result, it is one of the lead partners of the NCSS. To meet the modern-day soil inventory objectives, the NCSS program encompasses all lands of the United States, including wetlands, forested areas, rangelands, and urban areas (Table 9.1).

Early soil scientists were pioneers in their field and, therefore, encountered many challenges. One of the biggest problems they faced was the lack of base layers, such as topographic maps, aerial images, or other resource inventories. With the advent of commercial aviation in the 1920s, aerial photography became increasingly available and was incorporated into the soil survey process. In 1931, the first stereoscopes were used in Michigan, which was a transformative technological leap in the ability to see and segment landforms. The use of stereoscopes was so valuable that they were not phased out until geographic information systems (GIS) were widely incorporated in the early to mid-2000s. Today, almost all soil scientists are trained in the use of GIS and know how to display, create, and manipulate digital base

Table 9.1 Number of hectares of different land categories in the continental United States (CONUS) that are mapped in the Soil Survey Geographic (SSURGO) database

\begin{tabular}{|c|c|c|}
\hline Category & $\begin{array}{l}\text { Hectares of } \\
\text { SSURGO } \\
\text { mapped in } \\
\text { CONUS }\end{array}$ & Description \\
\hline Rangeland & $\begin{array}{l}262396 \\
147\end{array}$ & $\begin{array}{l}\text { Includes all areas identified as } \\
\text { grassland/herbaceous or shrub/scrub in } \\
\text { the National Land Cover Dataset. }\end{array}$ \\
\hline Forest & $\begin{array}{l}175809 \\
364\end{array}$ & $\begin{array}{l}\text { Includes all areas identified as } \\
\text { deciduous, evergreen, or mixed forest in } \\
\text { the National Land Cover Dataset. }\end{array}$ \\
\hline Urban & 44154084 & $\begin{array}{l}\text { Includes all areas identified as } \\
\text { developed open space, developed low } \\
\text { intensity, developed medium intensity, } \\
\text { and developed high intensity in the } \\
\text { National Land Cover Dataset. The } \\
\text { SSURGO data does not always } \\
\text { recognize urban land in the map unit } \\
\text { concepts and instead recognizes it as } \\
\text { native undisturbed soil. }\end{array}$ \\
\hline Wetlands & 39313672 & $\begin{array}{l}\text { Includes all areas identified as woody or } \\
\text { emergent herbaceous wetlands in the } \\
\text { National Land Cover Dataset. }\end{array}$ \\
\hline Barren & 7559042 & $\begin{array}{l}\text { Includes all areas identified as barren } \\
\text { land (rock/sand/clay) in the National } \\
\text { Land Cover Dataset. }\end{array}$ \\
\hline $\begin{array}{l}\text { Perennial } \\
\text { ice/snow }\end{array}$ & 87924 & $\begin{array}{l}\text { Includes all areas identified as perennial } \\
\text { ice/snow in the National Land Cover } \\
\text { Dataset. }\end{array}$ \\
\hline
\end{tabular}

layers for the purposes of developing pre-maps and final publication polygon layers.

With the rapid advancement in digital soil mapping techniques, the next major phase of soil surveying is underway. Much of the United States has been inventoried in the last 118 years, yet many areas lack high-quality data. It is anticipated that as digital soil mapping (DSM) is incorporated into the NCSS program, soil inventories will be generated for these lands at an accelerated pace. For example, in 2011, the NRCS Soil Survey Geographic (SSURGO) program published their first certified DSM mapping effort in Essex County, Vermont (Soil Survey Area VT009). This was quickly followed by DSM or DSM-assisted soil surveys in Florida, Minnesota, North Dakota, Texas, Washington, Wyoming, and Utah. While the NRCS is moving forward with DSM soil mapping, the use of this technique on Forest Service lands has been limited. The most successful use of DSM on Forest Service lands has been a joint effort between NRCS and the Forest Service encompassing Soil Survey Area MN613 within the Boundary Waters Canoe Area Wilderness on the Superior National Forest in the Northeastern Region. This collaborative effort produced a DSM-generated raster map of soil map units and an associated polygon vector map by bringing together several agency soil scientists and employing multiple modeling approaches and high-resolution topography data derived from LiDAR (light detection and ranging) methods (Fig. 9.1). Other DSM mapping efforts are ongoing, including mapping of volcanic ash mantles in the Forest Service's Northern Region, a soil feature that, due to its high water holding capacity, plays a critical role in alleviating late summer plant drought stress.

Methods for managing, storing, and delivering soil information have also evolved over the last 118 years. Surveys were typically conducted on a county-by-county basis, with a strong emphasis placed on matching and correlating information across political boundaries. Federal land management areas, such as national forests, national parks, or BLM districts, were also used in place of county boundaries, particularly in the western states. Hard copy manuscripts were handwritten and printed for each area surveyed. These reports contained the soil maps, which were typically overlaying orthorectified aerial images, along with tables of data information about the soil properties and interpretations. In 1972, the soil survey program entered the computer age, and tabular information began to be stored in a mainframe national database at Iowa State University. In the $1990 \mathrm{~s}$, soil maps were transferred to a digital format, and the first version of the Soil Survey Geographic (SSURGO) database was created (Fig. 9.2). In 2003, the Web Soil Survey program was released, which allowed users to easily interface with and access soil information through the Internet (Soil Survey Staff 2017). While improvements continue to be made and new tools and prod- 
A
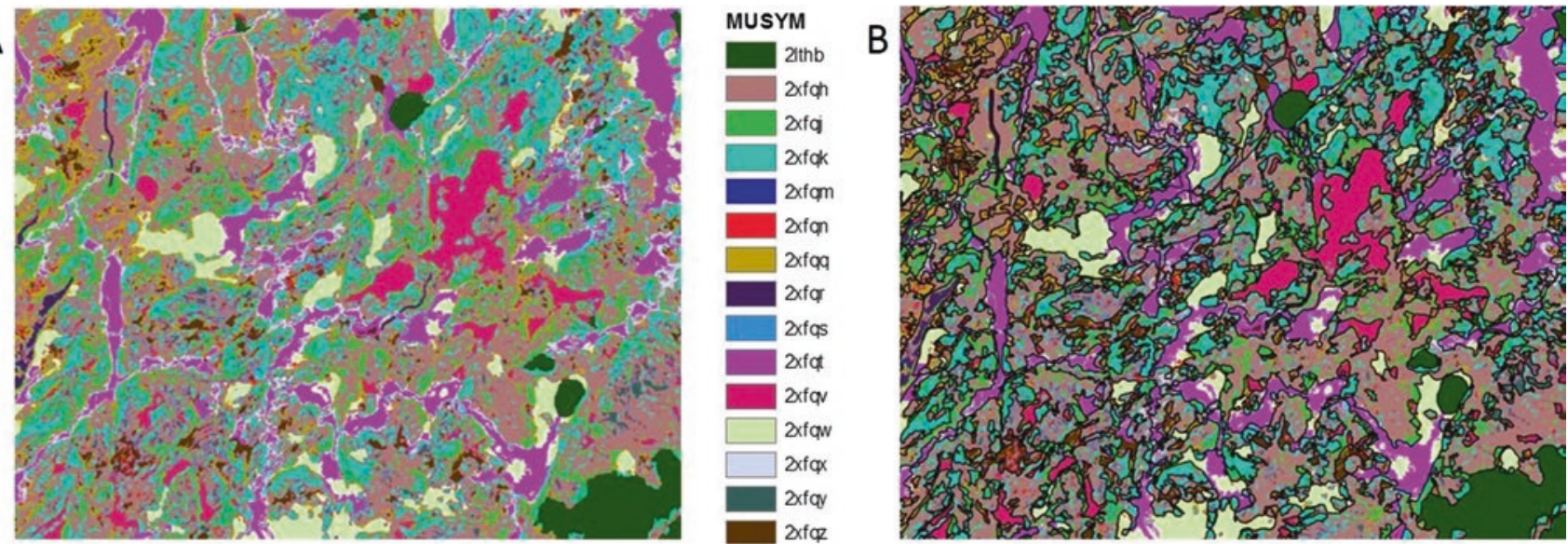

Fig. 9.1 Soil Survey Geographic (SSURGO) soil maps from the Boundary Waters Canoe Area Wilderness, Superior National Forest (MN613; St. Louis County, Minnesota, Crane Lake Part): (a) Component-level USDA NRCS SSURGO raster $(10 \mathrm{~m})$ soil survey

where each pixel represents an individual soil map unit component, and (b) SSURGO soil map unit polygons on top of the raster soil map unit component map

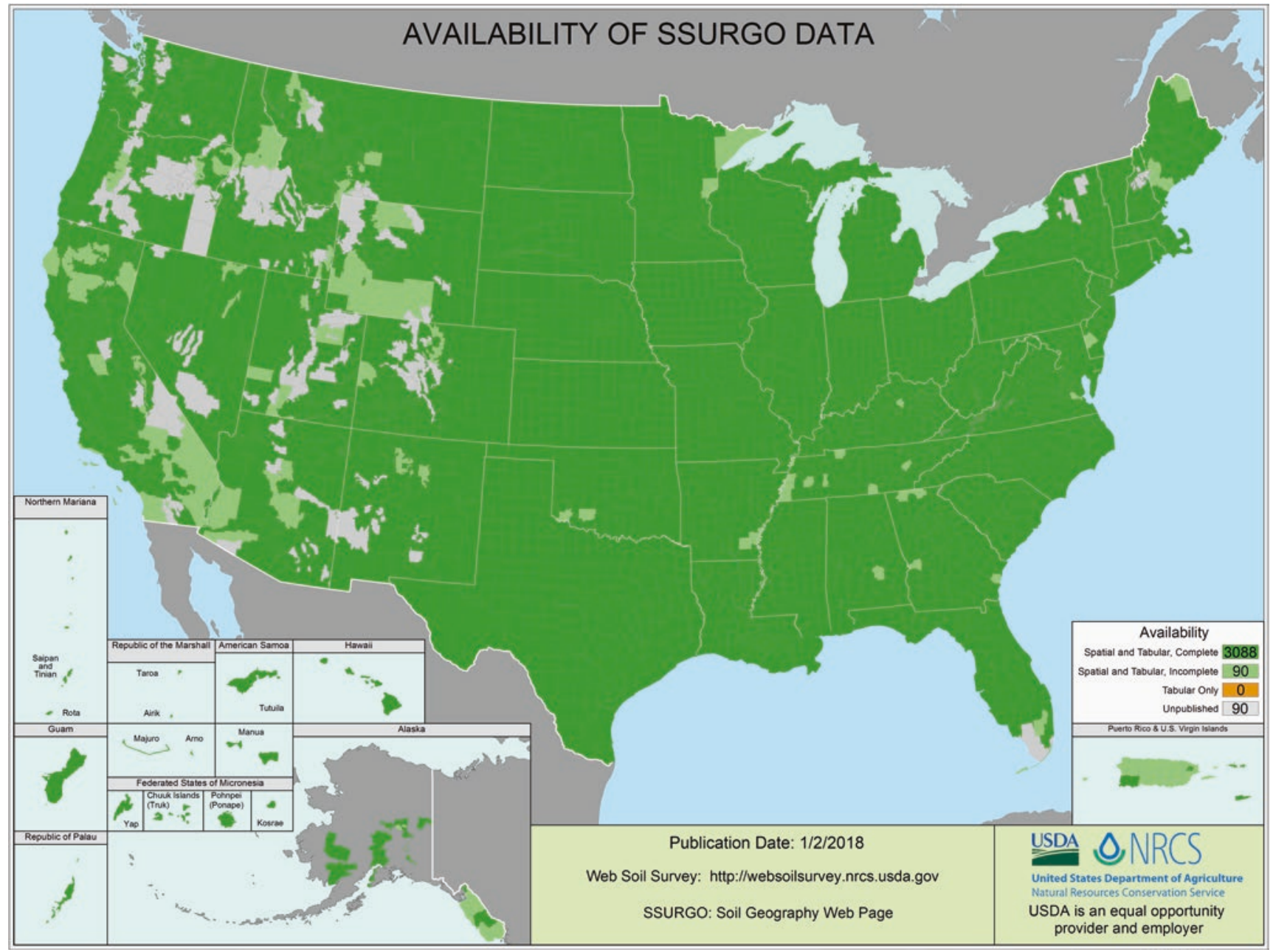

Fig. 9.2 Status of Soil Survey Geographic (SSURGO) mapping in the United States and its Island Territories 
ucts are developed, the NCSS soil survey program concurrently seeks to address the form and function of products and services necessary to meet future demands. Fundamentally, this process assesses how NCSS partner organizations collect, develop, manage, and deliver soil information. This transformative process often requires cultural shifts in organizational operations, as well as changes to NCSS standards, a process that requires time, considerable foresight, and agency cooperation.

\section{Methods}

\section{Traditional Soil Mapping}

Traditional soil maps are typically generated at a 1:24,000 scale (or coarser). This scale can preclude a soil mapper from spatially delineating differing soil characteristics that occur at finer map scales, often a result of changes in topographic features such as slope or aspect. Thus, mappers rely on component mapping. Component mapping creates a single map unit delineation that is composed of more than one soil type, with a specific soil type location described in the attribute data but not represented in the spatial data. An example is a single soil map unit named "Alpha-Beta complex, 3 to 20 percent slopes." This map unit contains two major soils, Alpha and Beta, called components, which have dissimilar properties but cannot be mapped separately at the scale of mapping being used.

The first step in soil mapping is the development of premaps. Pre-maps are an inventory of soil map units and their relative position on the landscape based on landform. Next, a substantial amount of time is spent collecting field data for the purposes of validating, updating, and refining the soil landform model. Field work includes describing the soil horizons, identifying the type and cover of plants, identifying any historic pre-European plant communities, denoting landforms, establishing soil sample transects, measuring water tables, recording evidence of flooding and ponding, identifying geologic formations, and traversing landforms. Field work is followed by model adjustment, refinement of soil map unit concepts, final line placement, and generation of tabular soil data from the field and laboratory data. While this is considered "traditional soil mapping," it does include the use of multiple digital data inputs to develop, refine, validate, and finalize predictive models and soil survey maps. These digital inputs include point data layers, aerial imagery, infrared satellite images, topographic layers, geologic layers, vegetation inventories, landform layers, climate data, other soil inventories, digital elevation models (DEMs), and numerous DEM derivatives. The DEM derivatives include products such as hillshade, slope, aspect, wetness index, slope shape, solar radiation models, and customized combination of derivatives.

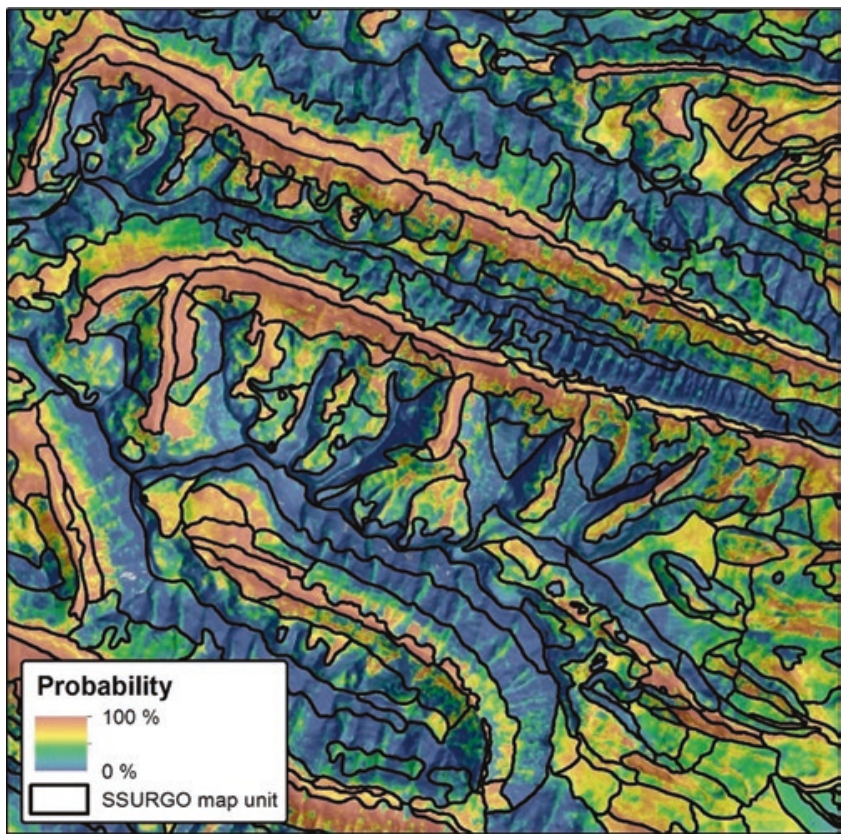

Fig. 9.3 Map showing percent probability of volcanic ash occurrence on the Bitterroot National Forest in Montana overlain by Soil Survey Geographic (SSURGO) map unit polygons (black lines). Red colors indicate a higher probability of ash-mantled soils and blue colors indicate lower probability of occurrence. Mapping individual soil characteristics using digital soil mapping techniques is helping land managers identify timber suitability and reforestation potential in forested landscapes in the western United States. (Source: MT647; Bitterroot National Forest Area, Montana. Raster resolution 30 m)

In the future, the delivery of traditional soil map information will most likely transition from vector (line delineated) products to raster (pixel based) products (Fig. 9.3). Raster products will have finer spatial resolution as modeling and interpretation techniques improve. Soil data for large geographic areas will be available at faster speeds through both desktop and mobile platforms. Data that are now delivered as a map unit will begin to be parsed out into specific soil components for continuous soils classes, or entirely new inventory products will be generated using modern DSM techniques. For example, one of the newer automated mapping products is called SoilGrids $1 \mathrm{~km}$. This mapping product presents global three-dimensional soil information at a $1 \mathrm{~km}$ resolution and contains information on soil properties at six standard depths while also incorporating laboratory analyses of soil carbon (C), $\mathrm{pH}$, sand, silt, clay, depth to bedrock, and more (Hengl et al. 2014). SoilGrids $1 \mathrm{~km}$ can consistently use soil spatial data for input into global models.

\section{Digital Soil Mapping}

Digital soil mapping, a relatively new field of soil science initiated in the late twentieth century, continues to evolve as digital technology advances in computational power and memory. Digital soil mapping focuses on developing raster- 


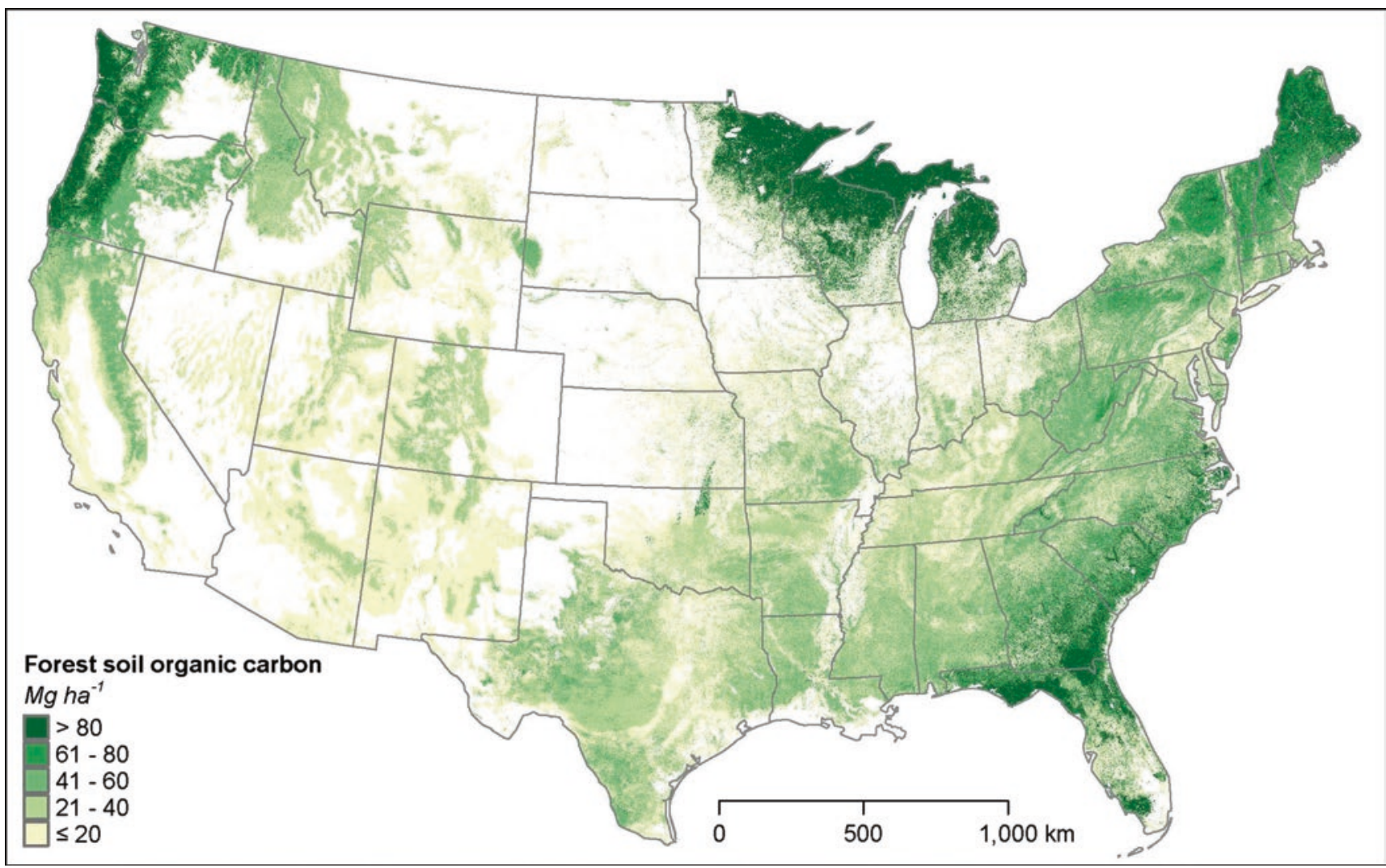

Fig. 9.4 Soil organic C density imputed from USDA Forest Service Forest Inventory and Analysis (FIA) plots in the conterminous United States for 2000-2009. (Source: Wilson et al. 2013, used with permission)

based soil information through computer modeling of fieldbased soil observations and associated environmental data (Lagacherie and McBratney 2007; Minasny and McBratney 2016; Soil Science Division Staff 2017). A commonly cited basis for DSM is presented by McBratney and others (2003), who propose that soil properties can be spatially modeled by placing a geographic context to Jenny's (1941) soil formation factors; i.e., $\mathrm{S}=\mathrm{f}$ (cl, o, r, p, t) where natural soil bodies on the landscape (S) are a function of climate (cl), organisms (o), relief or topography (r), soil parent material (p), and time (t). Modern computer software and hardware advances coupled with free remotely sensed imagery (e.g., Landsat TM) and high-resolution DEM models have allowed DSM to move from a purely academic exercise to a fully operational mapping system employed within the NCSS.

A unique feature of DSM products relative to traditional soil maps is the ability to map a suite of soil properties (e.g., map unit component) or a single soil property (e.g., soil organic C) continuously across the landscape at varying pixel sizes (Soil Science Division Staff 2017; Wilson et al. 2013) (Fig. 9.4). Digital soil mapping also provides the capability to rapidly update map products as new information, such as field observations or higher-resolution environmental features, become available. As with all models, some error will be associated with any prediction. However, DSM provides a distribution of prediction errors for each raster pixel, providing end users an ability to assess map suitability for inclusion in other models or for informing management, regulatory, and policy decisions (Soil Science Division Staff 2017).

A sample of methodologies often employed during the course of a DSM project can include supervised (analyst based) or unsupervised (computer based) spectral classification, linear and logistic regression, kriging, and fuzzy logic. More complex techniques involve classification and regression trees and deep learning algorithms such as neural networks. Most DSM projects do not rely on the use of just a single model or software tool, but use a hybrid approach that requires multiple methodologies based on the training and skills of the soil scientist. Often the model performance and accuracy will dictate the need for the scientist to adjust and try a different approach.

Several recent DSM efforts to model both continuous soil properties and soil classes at continental scales have made major advances in the DSM field by employing cloud computing and high-performance computing (HPC) platforms. Chaney and others (2016) used the parallelized classification regression tree approach called disaggregation and harmoni- 
zation of soil map units through resampled classification trees (DSMART) to map soil series across the continental United States at a $30 \mathrm{~m}$ resolution. More recently, Ramcharan and others (2018) developed both soil class (soil taxonomy) and soil property maps for the lower 48 states at a $100 \mathrm{~m}$ resolution, using both a simple random forest classification tree-based approach for soil class maps and model averaging of tree-based models where model predictions are averaged across all model outputs.

\section{Soil Monitoring and Assessment}

Monitoring refers to the repeated collection and archiving of data that serves a defined purpose, such as determining impacts from management actions. Monitoring is structured, targets biophysical factors (e.g., soil, water, plant cover, crops), and documents dynamic processes (e.g., hydrologic function) over relatively long periods of time (e.g., years to decades). This is different from research studies, which usually collect a limited set of observations or measurements over a relatively short period to be used for hypothesis testing (Vogt et al. 2011). An assessment is a critical evaluation of information for purposes of guiding decisions on a complex, public issue or to develop restoration strategies for degraded lands. Assessments evaluate the state of a process at a time and place. They are often repeated and can inform policy, but they are usually not prescriptive (Reed et al. 2011). Assessments synthesize complex phenomena such as climate change or land degradation. For this document, monitoring and assessment are treated as a continuum of effort, with one often informing the other.

There are two approaches to monitoring and assessment: (1) operational monitoring and (2) monitoring-to-learn. Operational monitoring (effectiveness monitoring) is designed to inform an ecosystem or species' trajectory and to make timely interventions when necessary (Noon et al. 1999) or to set benchmarks for restoration success (Block et al. 2001). Operational monitoring is a method for keeping an ecosystem within bounds of acceptability and operating within normal ranges. Sometimes this takes the form of compliance or implementation monitoring, where managers monitor and report actions about the landscape or watershed conditions in order to directly inform course corrections. It also provides understanding about the management objectives and implementation efficiency. Operational monitoring also includes monitoring the design and objectives of a management strategy (Herrick et al. 2006).

Monitoring-to-learn is broadly a monitoring approach designed to understand the ecological system; this approach has a fundamentally different purpose than operational monitoring. While operational monitoring connects outcomes to circumstances and actions, dynamic ecosystems require long-term monitoring (monitoring-to-learn) to clarify the role of a sequence of conditions and actions. This is particularly true when the timing of an action becomes important in determining the outcome. Monitoring-to-learn expands on operational monitoring and can include a range of operating conditions or practices so that current actions can inform future management or restoration methods for a given ecosystem or function. Such a monitoring strategy provides an understanding of how ecosystems respond to both natural and anthropogenic disturbances, which in turn can provide intervention when ecosystems are not responding to restoration efforts. This knowledge can often be the difference between restoration success and failure. Consequently, the design and development of monitoring-to-learn programs will make monitoring data more scientifically robust (Ewen and Armstrong 2007) and usable for determining management success or developing other goals and strategies (MacMahon and Holl 2001).

\section{US Monitoring and Assessment Installations}

\section{Long-Term Ecological Research Sites}

The United States has a rich history of environmental research and monitoring through the Long-Term Ecological Research (LTER) network of place-based field sites supported by a combination of Federal, state, and private organizations that are distributed across the country (Fig. 9.5). The datasets from these sites, some spanning decades and even centuries, have been gathered from a single location with similar methods by overlapping generations of multidisciplinary teams of scientists. LTER sites provide the United States with a valuable network capable of monitoring longterm changes in climate, air quality, soils, water quantity and quality, vegetation distribution and productivity, and the spread of pests, pathogens, and invasive species. These data also provide historical perspectives that are valuable when evaluating ecosystem responses to extreme perturbations, including weather events, fire, pest outbreaks, or pathogen outbreaks. Additionally, they contribute context for scientific field and laboratory experiments and parameterization for ecosystem, regional, and earth system models. Although sometimes criticized as being costly, the LTER program has provided the foundation for important scientific discoveries and critical information for environmental policymaking and decision-making (Lovett et al. 2007).

\section{Forest Inventory and Analysis (FIA) Program}

While LTER sites represent intensive place-based monitoring, the Forest Inventory and Analysis (FIA) program provides extensive nationwide environmental monitoring across a variety of spatial scales (Fig. 9.6) and soil attributes (Amacher and Perry 2010; O’Neill et al. 2005; Woodall et al. 
Fig. 9.5 Map of the Long-Term Ecological Research (LTER) sites across North America, United States Territories, and Antarctica. (Source: LTER-NCO [CC BY-SA 4.0.], via https:// lternet.edu/graphic-resources/ [accessed April 16, 2019])

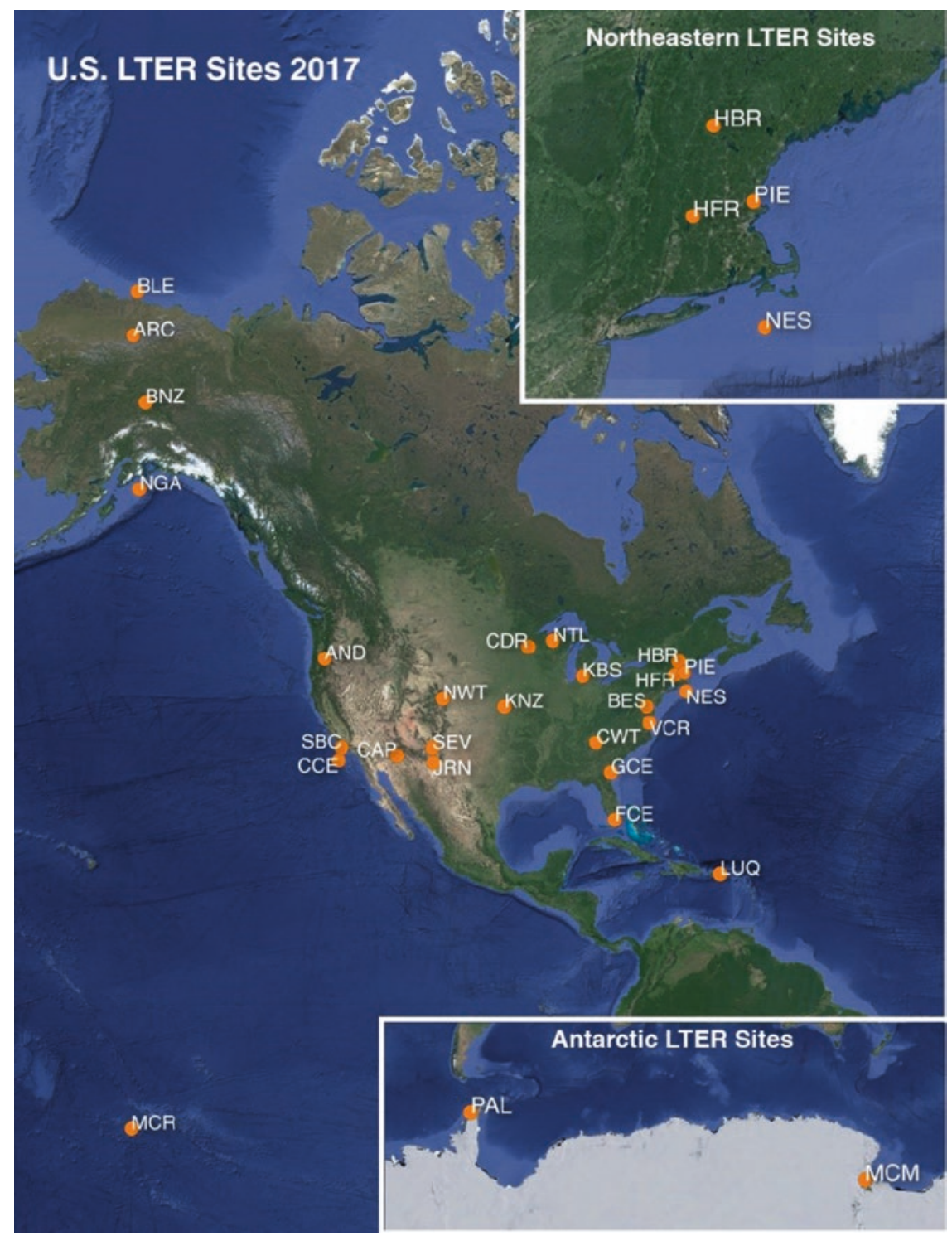

2011). Founded in the 1930s, FIA is a plot-based inventory program. Today, the plot network remains at the heart of the inventory's ability to document the status and trends of the nation's forest resources. The FIA program has a long history of sharing data that support its various assessments. These data have traditionally been provided both in downloadable formats on dedicated websites and through custom tools facilitating a user's quest to generate queries and answers. It's increasingly clear that these data, while publicly available, remain too complex or too cryptic to use by many. To overcome this, FIA is producing authoritative map products with associated accuracies (Riemann et al. 2010; Wilson et al. 2013) that may be downloaded or ingested directly into platforms like Environmental Systems Research Institute, Inc. (ESRI $\left.{ }^{\circledR}\right)$ ArcGIS Online.

The Forest Inventory and Analysis program also plays a powerful role in providing training data for models leverag- ing remotely sensed imagery and ancillary data. Domke and others $(2016,2017)$ leveraged digital representations of soil forming factors (climate, topography and relief, parent material), land cover, and data from the International Soil Carbon Network (http://iscn.fluxdata.org/) to impute observations of soil C on 3636 plots to all plots in the FIA database. Such an approach, in concert with in situ observations, makes the FIA $\mathrm{C}$ data more responsive to variation across the landscape and management activities. This is a considerable advancement over past methods, which typically estimated forest floor $\mathrm{C}$ as a function of forest type and stand age (Smith and Heath 2002) and forest soil organic $C$ as a fusion of the State Soil and Geographic (STATSGO) database with FIA's forest type groups (Amichev and Galbraith 2004). For example, empirically driven FIA models found that estimated forest litter C stocks were significantly overstated, while soil organic C stocks were significantly understated. This resulted in a 
Fig. 9.6 Example of the FIA monitoring framework and the scaling network leading to assessment of forested landscapes. (Source: Amacher and Perry 2010)

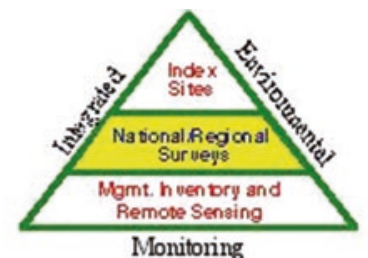

\section{USDA Forest Service Integrated Monitoring} Framework

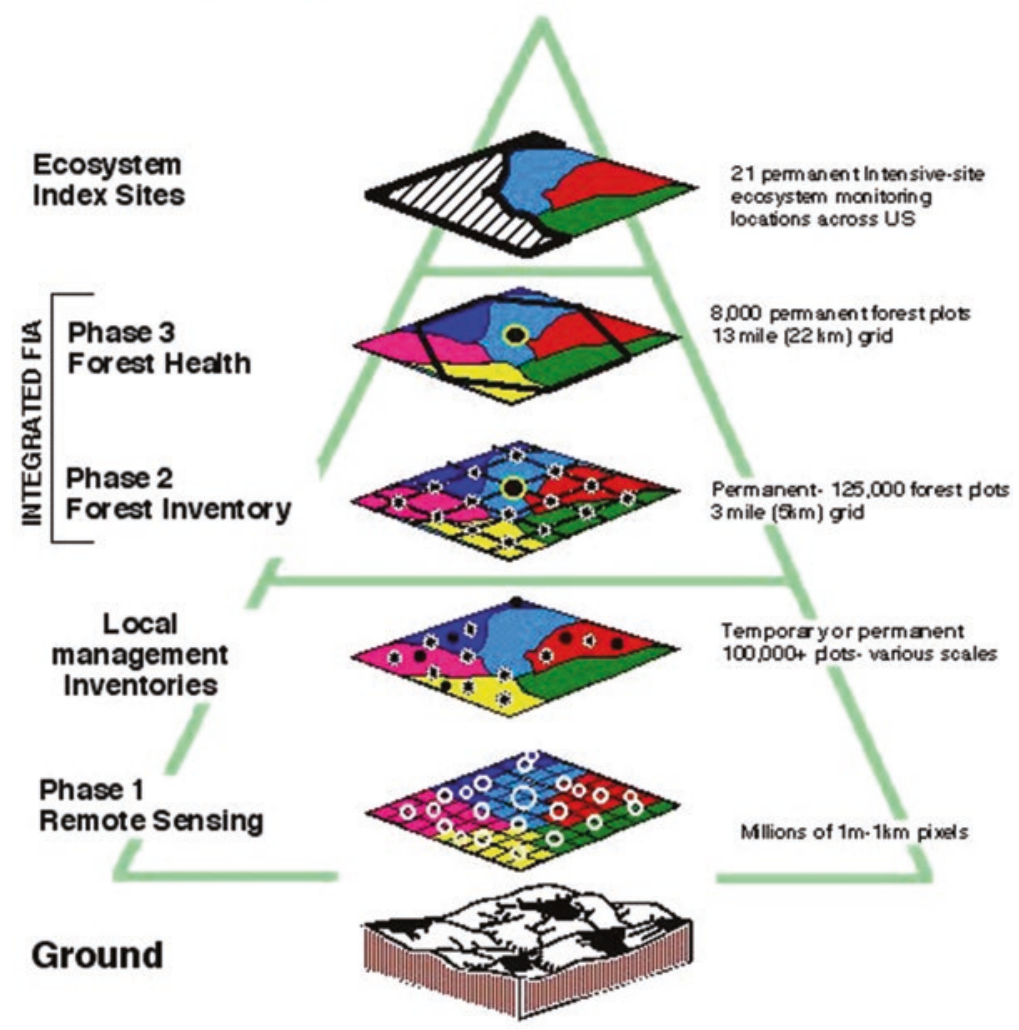

marked decrease in the litter/soil $\mathrm{C}$ ratio from 0.30 (18.77 $\mathrm{Mg} \mathrm{ha}^{-1}: 62.87 \mathrm{Mg} \mathrm{ha}^{-1}$ ) based on the historical models to 0.09 (9.99 $\mathrm{Mg} \mathrm{ha}^{-1}: 109.66 \mathrm{Mg} \mathrm{ha}^{-1}$ ) (Domke et al. 2016, 2017). Such findings further illustrate the value of FIA as the official source of national forest and soil $\mathrm{C}$ stocks at the US Environmental Protection Agency and the United Nations Framework Convention on Climate Change (US EPA 2017).

\section{"Smart" Environmental Sensor Technology}

Historically, LTER and FIA monitoring data were obtained across an array of temporal sampling periods by teams of field technicians who relied on mechanical sampling devices. The advent of "smart" environmental monitoring technology with advances in digital sensors, wireless data transmission, and a new generation of data mining and visualization techniques is making high-frequency, high-quality data available on the Internet in near real time, and it is revolutionizing the field of environmental science and monitoring (Fig. 9.7). By providing near real-time data for environmental parameters related to droughts, floods, fires, and other extreme events, these sensor systems offer a new generation of warning devices for known and unknown environmental threats.
These digital devices are routinely deployed at individual research sites across the country and are increasingly being used to connect networks of research sites in real time (e.g., Forest Service's Smart Forest Network). The most ambitious program is the National Science Foundation's NEON program, with 20 domain sites and 40 satellite sites distributed across environmental gradients in the continental United States. Rather than being a bottom-up network of independent sites established historically to address local or regional issues, NEON was envisioned to be an integrated, scientific infrastructure that enables research, discovery, and education about ecological change at a continental scale, equipped with the most advanced digital sensors and monitoring systems.

\section{Guidelines}

Effective monitoring and assessment require methods that are adaptable to local and regional ecological settings yet provide standardized protocols that can be uniformly applied regardless of location. To meet this need following the enactment of the National Forest Management Act of 1976, the 


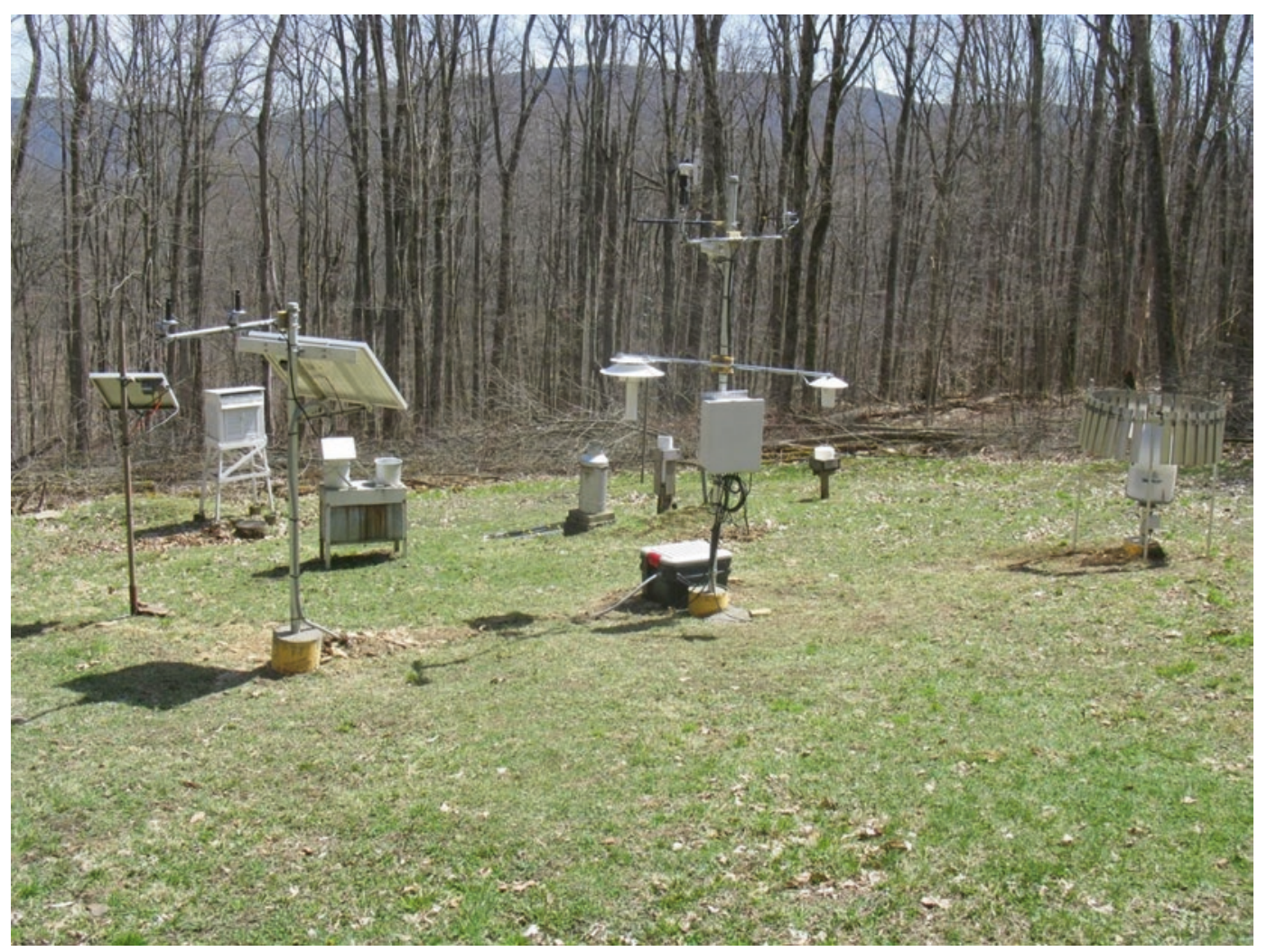

Fig. 9.7 Smart sensor array monitoring of soil and atmospheric properties in real-time. (Photo credit: Ian Halm, USDA Forest Service)

Forest Service developed soil quality standards and guidelines to evaluate changes in forest soil productivity and sustainability after land management operations (Page-Dumroese et al. 2000). Additionally, soil productive capacity in the United States is also governed by many policies, but foremost among them are the Multiple Use Sustained Yield Act of 1960, the National Environmental Policy Act of 1969, and the Forest and Rangeland Renewable Resources Planning Act of 1974. Forest industry members of the American Forest and Paper Association must satisfy the requirements of the Sustainable Forestry Initiative (SFI) for soil productivity by using strategies appropriate to soil, topography, and climate. Soil indicators became part of the FIA program's suite of observations (O'Neill et al. 2005) as an outcome of collaboration with the EPA's Environmental Monitoring and Assessment program and the Forest Service's Forest Health Monitoring program. These programs developed the tools needed to monitor and assess the status and trend of national ecological resources at multiple spatial and temporal scales (Pellant et al. 2005).

Like forested regions, guidelines for maintaining rangeland productivity focus on soil and site stability, watershed function, and biotic integrity (Herrick et al. 2005). Rangeland monitoring guidelines generally follow a list of steps to select and interpret soil quality indicators: (1) identify a suite of indicators that are consistently correlated with the func- tional status of one or more critical ecosystem processes; (2) select indicators based on inherent soil and site characteristics and on site-specific or project-specific resource concerns (e.g., erosion, invasive species); (3) use spatial variability in developing and interpreting indicators to make them more representative of ecological processes; and (4) interpret indicators in the context of an understanding of dynamic, nonlinear ecological processes defined by thresholds (Herrick et al. 2002).

Identifying key soil properties that serve as indicators of soil function is complicated when assessing forest or rangeland soil quality. Soil compaction, erosion, and organic matter losses attributable to a variety of different management actions (Burger 2002; Powers et al. 1990) are the main factors that contribute to declines in ecosystem productivity. These factors alter $\mathrm{C}$ allocation and storage, nutrient content and availability, water storage and flux, rhizosphere processes, and insect and disease dynamics (Neary et al. 2010). Practical assessment of soil quality requires consideration of all these functions and their variations in space and time (Amacher et al. 2007; Larson and Pierce 1991).

The FIA soil indicator protocol and other soil monitoring guidelines developed by public and private agencies are designed to specifically measure status of and trends in soil erosion, compaction, internal drainage, organic matter (soil organic C), physiochemical properties, contributions to the 
global $\mathrm{C}$ budget, and accumulations of toxic substances (Amacher and Perry 2010; O'Neill et al. 2005). These data can be used to assess (1) productivity and sustainability of forest or range ecosystems, (2) conservation of soil and water resources, (3) contributions of forest and rangeland soils to the global climate cycle, and (4) accumulation of persistent toxic substances.

Strong policy requirements are increasing the need for effective soil monitoring at many scales. Monitored soil properties represent aggregated soil processes such as decomposition, nutrient cycling, water retention, and microbial populations (Ritz et al. 2004). There are many indicators in the numerous monitoring schemes across the United States. Therefore, the monitoring data are collated into an assessment or framework to facilitate the determination of trends and status at a larger scale (e.g., Perry and Amacher 2009, 2012) in order for the monitoring data to be comprehensible and useful for land managers and policymakers. Monitoring data can be used as an "early warning" system and can steer management away from detrimental impacts to soil quality.

Reliable monitoring protocols have also been identified as critical components of any adaptive management process for forest and rangeland soil conservation programs (Curran et al. 2005; Reeves et al. 2013). These protocols must provide uniform and unambiguous definitions of soil disturbance categories that relate to ecosystem productivity and hydrologic function (Page-Dumroese et al. 2012). For example, the Forest Soil Disturbance Monitoring Protocol (FSDMP) (Page-Dumroese et al. 2009) was designed based on pioneering monitoring efforts in the Pacific Northwest Region (Howes et al. 1983). The FSDMP uses visual soil disturbance classes, a common terminology, and has an accessible database, yet employees can quickly and easily be trained on how to use it (Table 9.2). In an era of declining budgets for monitoring, the database provides critical information for wisely determining where and when to monitor, as well as being able to leverage monitoring efforts across landscapes and ownerships (Page-Dumroese et al. 2012).

In summary, long-term research records, especially when coupled with targeted research networks and remote sensing, are critical tools for monitoring the health of the nation's forests and rangelands while providing the scientific basis for natural resource policy and management decision-making. Long-term data have already served to detect short- and longer-term environmental changes at local, regional, and continental scales and have been a source for scientific discoveries on historical and current environmental issues. A need exists to unify and synthesize data across all these platforms, with the promise to address socio-ecological issues of today, as well as to answer future questions not yet imagined.
Table 9.2 Definitions of visual indicators of detrimental soil disturbances from the Forest Soil Disturbance Monitoring Protocol (PageDumroese et al. 2012)

\begin{tabular}{l|l}
\hline $\begin{array}{l}\text { Visual } \\
\text { disturbance }\end{array}$ & Definition \\
\hline $\begin{array}{l}\text { Forest floor } \\
\text { impacted }\end{array}$ & $\begin{array}{l}\text { Forest floor material includes all organic } \\
\text { horizons above the mineral soil surface. }\end{array}$ \\
\hline $\begin{array}{l}\text { Topsoil } \\
\text { displacement }\end{array}$ & $\begin{array}{l}\text { The surface mineral soil primarily includes the A } \\
\text { horizons, but if the A horizon is shallow or } \\
\text { undeveloped, it may include other horizons. This } \\
\text { disturbance is usually due to machinery but does } \\
\text { not include rutting (described below). }\end{array}$ \\
\hline $\begin{array}{l}\text { Rutting } \\
\text { Ruts vary in depth but are primarily the result of } \\
\text { equipment movement. Ruts are defined as } \\
\text { machine-generated soil displacement or } \\
\text { compression. Often soil puddling is present } \\
\text { within the rut. }\end{array}$ \\
\hline $\begin{array}{l}\text { Burning (light, } \\
\text { severe) }\end{array}$ & $\begin{array}{l}\text { Burn severity includes only effects on the forest } \\
\text { floor and mineral soil, not on aboveground } \\
\text { vegetation. }\end{array}$ \\
\hline Compaction & $\begin{array}{l}\text { Compaction by equipment results in either a } \\
\text { compression of the soil profile or increased } \\
\text { resistance to penetration (or both). }\end{array}$ \\
\hline $\begin{array}{l}\text { Platy structure } \\
\text { (massive or } \\
\text { puddled) }\end{array}$ & $\begin{array}{l}\text { Flat-lying or tabular structure in the mineral soil. } \\
\text { Massive indicates no structural units are present } \\
\text { and soil material is a coherent mass. Puddled soil } \\
\text { is often found after wet weather harvest } \\
\text { operations (soil pores are smeared to prevent } \\
\text { water infiltration). }\end{array}$ \\
\hline
\end{tabular}

\section{Tools and Technology}

\section{Web Soil Survey (WSS)}

Web Soil Survey provides soil data and information produced by the NCSS. It is operated by the NRCS and provides access to the largest natural resource information system in the world. The Natural Resources Conservation Service has soil maps and data available online for more than 95 percent of the Nation's counties, and they anticipate having data available for 100 percent of the counties in the near future. The site is updated and maintained online as the single authoritative source of soil survey information (https://websoilsurvey.nrcs.usda.gov/).

\section{Gridded Soil Survey Geographic (gSSURGO) Database}

The gridded Soil Survey Geographic (gSSURGO) database is similar to the standard NRCS SSURGO database product, but it is in the format of an ESRI ${ }^{\circledR}$ file geodatabase. A file geodatabase has the capacity to store much more data, and thus greater spatial extents, than the traditional SSURGO product, which makes it possible to offer these data in statewide or even conterminous United States (CONUS) tiles. The gSSURGO database contains all the original soil attri- 
bute tables in SSURGO. All spatial data are stored within the geodatabase instead of externally as separate shapefiles. Both SSURGO and gSSURGO are considered products of the NCSS partnership. The gSSURGO dataset was created for use in national, regional, and statewide resource planning and analysis of soil data. The raster map layer data can be readily combined with other national, regional, and local raster layers, including the National Land Cover Database (NLCD), the National Agricultural Statistics Service (NASS) Crop Data Layer (CDL), and the National Elevation Dataset (NED) (https://www.nrcs.usda.gov/wps/portal/nrcs/detail/ soils/home/?cid=nrcs142p2_053628).

\section{Soil Data Viewer (SDV)}

The Soil Data Viewer (SDV) tool, built as an extension to ESRI $^{\circledR}$ ArcMap, allows a user to create soil-based thematic maps. The application can also be run independent of ArcMap, but output is then limited to a tabular report. The soil survey attribute database associated with the spatial soil map is a complicated database with more than 50 tables. Soil Data Viewer provides users access to soil interpretations and soil properties while shielding them from the complexity of the soil database. Each soil map unit, which is typically a set of polygons, may contain multiple soil components that have different uses and management. With SDV, the end user can compute a single soil characteristic value for a map unit and spatially display the results, relieving the burden of querying the soil database, processing the data, and linking it to a spatial map. To ensure appropriate use of the data, SDV also contains processing rules, which provide the user with a tool for quick geospatial analysis of soil data for use in resource assessment and management (https://www.nrcs.usda.gov/wps/portal/nrcs/ detailfull/soils/home/?cid=nrcs142p2_053620).

\section{ESRI $^{\circ}$ ArcGIS Soil Inference Engine (ArcSIE)}

ArcSIE is one of the most common software tools used in operational digital soil modeling today. It was developed by Xun Shi at Dartmouth University to utilize a soil scientist's knowledge of soil landscape relationships and fuzzy logic to infer soil classes across the landscape (Shi et al. 2009). ArcSIE is primarily intended for use in areas with existing knowledge of the soil-landscape relationships, but it is being successfully employed in areas undergoing initial mapping, such as the White Mountain National Forest in the Northeast Region (Philippe, J. 2017. Personal communication. 2017. Soil Scientist, USDA NRCS, Soil Science Division, 481 Summer Street, Suite 202, St. Johnsbury, VT 05819.) (http:// www.arcsie.com/index.htm).

\section{Terrestrial Ecological Unit Inventory (TEUI) Geospatial Toolkit}

The Forest Service's Terrestrial Ecological Unit Inventory (TEUI) program developed the TEUI toolkit system to classify ecosystem types and map ecological units at different spatial scales. The TEUI system distinguishes among land areas that differ in important ecological factors, such as geology, climate, soils, hydrology, and vegetation. Maps and information about ecological units derived through the TEUI process are applied in land use planning to describe land capability and to identify suitability for various uses. The toolkit is used to accelerate the TEUI and soil survey mapping process, but it can also be used for other natural resource mapping efforts. The TEUI system is an ArcGIS extension that assists users in mapping and analyzing landscapes using geospatial data. The toolkit utilizes raster data (e.g., slope, aspect, elevation), polygon data (e.g., map units), and point data (e.g., soil pedon or vegetation plots) to calculate zonal statistics and display the results in tabular or graphical format. This software program was developed and is maintained by the Forest Service Geospatial Technology and Applications Center (GTAC) in Salt Lake City, UT (Fisk et al. 2010; Winthers et al. 2005) (https://www.fs.fed.us/soils/teui. shtml).

\section{Key Findings}

- The Natural Resources Conservation Service and the Forest Service provide hierarchically nested, multi-resolution soil mapping systems.

- The Forest Service provides integrated soil and vegetation ecological mapping products.

- Digital modeling continues to evolve, providing refined individual soil property map products.

- Long-term ecosystem monitoring installations provide a wide array of data useful in assessing land use and climate change effects on soil and vegetation patterns at multiple scales.

- Integration of terrestrial monitoring installations with remote sensing is providing near real-time assessments of changes in soil and vegetation properties.

- Guidelines and protocols developed by the Forest Service and other Federal agencies help to assess management impacts on ecosystem function and services and provide guidance in management and policy decision-making.

\section{Key Information Needs}

- Uniform, multi-scale soil mapping products for the United States and its Island Territories. 
- Data clearinghouses with consistent metadata for collaborative sharing across agencies and organizations.

- Integrated, multi-scale ecological surveys developed from both field and remotely sensed data.

- Standardized and appropriately scaled monitoring data to meet planning and management needs within the context of ecosystem services (providing clean water, healthy forests, and more) and habitat fragmentation.

- Linked monitoring and assessment data to evaluate changes in soil properties and ecosystem function.

- Increased assessments across all land use management projects.

- Acknowledgment at all levels of administration of the importance of assessing land use activity impacts on the soil resource.

- Increased understanding of legacy impacts on current management practices and a differentiation of current impacts from legacy effects.

- Initial and subsequent monitoring, assessment, or both of impacted areas to provide baseline data to guide adaptive management. Impacted areas include drought, wildfire, overgrazing, climate change, and insect/disease outbreaks, all of which have the potential to drastically change western ecosystem dynamics.

- Continued development of sound methods for monitoring, assessing, and managing ecological integrity.

\section{Literature Cited}

Abood SA, Maclean AL, Mason LA (2012) Modeling riparian zones utilizing DEMS and flood height data. Photogramm Eng Remote Sens 78(3):259-269

Amacher MC, Perry CH (2010) The soil indicator of forest health in the Forest Inventory and Analysis program. In: Page-Dumroese DS, Neary D, Trettin C (eds) Scientific background for soil monitoring on national forests and rangelands: Proceedings, RMRS-P-59. U.S. Department of Agriculture, Forest Service, Rocky Mountain Research Station, Fort Collins, pp 83-108

Amacher MC, O'Neil KP, Perry CH (2007) Soil vital signs: a new Soil Quality Index (SQI) for assessing forest soil health, Research Paper RMRS-RP-65. U.S. Department of Agriculture, Forest Service, Rocky Mountain Research Station, Fort Collins, $12 \mathrm{p}$

Amichev BY, Galbraith JY (2004) A revised methodology for estimation of forest soil carbon from spatial soils and forest inventory data sets. Environ Manag 33:S74-S86

Block WM, Franklin AB, Ward JP et al (2001) Design and implementation of monitoring studies to evaluate the success of ecological restoration on wildlife. Restor Ecol 9(3):293-303

Burger JA (2002) Environmental sustainability of forest energy production. 6.2: soil and long-term site productivity values. In: Richardson J, Smith T, Hakkila P (eds) Bioenergy from sustainable forestry: guiding principles and practices. Elsevier, Amsterdam. Chapter 6

Chaney NW, Wood EF, McBratney AB et al (2016) POLARIS: a 30-meter probabilistic soil series map of the contiguous United States. Geoderma 274:54-67
Coppin P, Jonckheere I, Nackaerts K, Muys B (2004) Digital change detection methods in ecosystem monitoring: a review. Int J Remote Sens 25:1565-1596

Curran MP, Miller RE, Howes SW et al (2005) Progress towards a more uniform assessment and reporting of soil disturbance for operations, research, and sustainability protocols. For Ecol Manag 220:17-30

Diamond DD, Elliott LF (2010) Ecological land type association modeling for East Texas, Final Report. U.S. Forest Service, National Forests and Grasslands in Texas, Lufkin

Diamond DD, Elliott LF (2015) Oklahoma ecological systems mapping interpretive booklet: methods, short type descriptions, and summary results. Norman: Oklahoma Department of Wildlife Conservation. Available at https://www.wildlifedepartment.com/lands-andminerals/eco-system-mapping.htm. Accessed 29 May 2020

Domke GM, Perry CH, Walters BF et al (2016) Estimating litter carbon stocks on forest land in the United States. Sci Total Environ 557-558:469-478

Domke GM, Perry CH, Walters BF et al (2017) Toward inventory-based estimates of soil organic carbon in forests of the United States. Ecol Appl 27(4):1223-1235

ECOMAP (1993) National hierarchical framework of ecological units. Unpublished administrative paper. Washington, DC: U.S. Department of Agriculture, Forest Service. Ecoregions of the United States [map, rev. ed.]. Robert G. Bailey, cartog. 1994. Washington, DC: U.S. Department of Agriculture, Forest Service. Scale 1:7,500,000; colored. $20 \mathrm{p}$

Ewen JG, Armstrong DP (2007) Strategic monitoring of reintroductions in ecological restoration programs. Ecoscience 14(4):401-409

Fisk H, Benton R, Unger C et al (2010) U.S. Department of Agriculture (USDA) TEUI Geospatial Toolkit: an operational ecosystem inventory application. In: Boettinger JL, Howell DW, Moore AC, Hartemink AE, Kienast-Brown S (eds) Digital soil mapping. Progress in Soil Science, vol 2. Springer, Dordrecht, pp 399-410

Forest and Rangeland Renewable Resources Planning Act of 1974; Act of August 17, 1974; 16 U.S.C. 1601

Helms D, Effland ABW, Durana PJ (2008) Profiles in the history of the U.S. soil survey. Wiley, New York, pp 327-331

Hengl T, Mendes de Jesus J, MacMillan RA et al (2014) SoilGrids1km: global soil information based on automated mapping. PLoS One 9(8):e105992

Herrick JE, Brown JR, Tugel AJ et al (2002) Application of soil quality to monitoring and management. Agron J 94(1):3-11

Herrick JE, Van Zee JW, Havstad KM et al (2005) Monitoring manual for grassland, shrubland and savanna ecosystems, Volume I: quick start. volume II: design, supplementary methods and interpretation. U.S. Department of Agriculture, Agricultural Research Service, Jornada Experimental Range, Las Cruces, 206 p

Herrick JE, Schuman GE, Rango A (2006) Monitoring ecological processes for restoration projects. J Nat Conserv 14:161-171

Howes S, Hazard J, Geist MJ (1983) Guidelines for sampling some physical conditions of surface soils, R6-RWM-145. U.S. Department of Agriculture, Forest Service, Pacific Northwest Region, Portland, $34 \mathrm{p}$

Jenny H (1941) Factors of soil formation. McGraw-Hill, New York

Lagacherie P, McBratney AB (2007) Spatial soil information systems and spatial soil inference systems: perspectives for digital soil mapping. In: Lagacherie P, Mcbratney AB, Voltz M (eds) Digital soil mapping: an introductory perspective. Elsevier, New York, pp 3-24

Larson WE, Pierce FJ (1991) Conservation and enhancement of soil quality. In: Evaluation for sustainable land management in the developing world, Vol. 2. IBSRAM Proc. 12(2). International Board for Research and Management, Bangkok, pp 175-203

Lovett GM, Burns DA, Driscoll CT et al (2007) Who needs environmental monitoring? Front Ecol Environ 5:253-260 
MacMahon JA, Holl KD (2001) Ecological restoration: a key to conservation biology's future. In: Soulé ME, Orians GH (eds) Conservation biology: research priorities for the next decade. Island Press, Washington, DC, pp 245-269

McBratney AB, Mendonça Santos ML, Minasny B (2003) On digital soil mapping. Geoderma 117:3-52

Minasny B, McBratney AB (2016) Digital soil mapping: a brief history and some lessons. Geoderma 264:301-311

Multiple-Use Sustained-Yield Act of 1960; Act of June 12, 1960; 16 U.S.C. 528 et seq

National Environmental Policy Act of 1969; Act of January 1, 1970; 42 U.S.C. 4321 et seq

National Forest Management Act of 1976; Act of October 22, 1976; 16 U.S.C. 1600

Natureserve (2019) Terrestrial Ecological Systems of the United States. http://services.natureserve.org. Accessed 6 Mar 2019

Neary DG, Trettin CC, Page-Dumroese DS (2010) Soil quality monitoring: examples of existing protocols. In: Page-Dumroese DS, Neary D, Trettin C (eds) Scientific background for soil monitoring on national forests and rangelands: Proceedings, RMRS-P-59. U.S. Department of Agriculture, Forest Service, Rocky Mountain Research Station, Fort Collins, pp 61-83

Noon BR, Spies TA, Raphael MG (1999) Conceptual basis for designing an effectiveness monitoring program. In: Mulder BS, Noon BR, Spies TA et al (eds) The strategy and design of the effectiveness monitoring program for the Northwest Forest Plan, General Technical Report, PNW-GTR-437. U.S. Department of Agriculture, Forest Service, Pacific Northwest Research Station, Portland, pp 49-68

O'Neill KP, Amacher MC, Perry CH (2005) Soils as an indicator of forest health: a guide to the collection, analysis, and interpretation of soil indicator data in the Forest Inventory and Analysis program, General Technical Report, NC-GTR-258. U.S. Department of Agriculture, Forest Service, North Central Research Station, St. Paul, $53 \mathrm{p}$

Page-Dumroese D, Jurgensen M, Elliot W et al (2000) Soil quality standards and guidelines for forest sustainability in northwestern. For Ecol Manag 138(1-3):445-462

Page-Dumroese DS, Rice TM, Abbott AM (2009) Forest soil disturbance monitoring protocol: Vol. II-supplementary methods, statistics, and data collection, General Technical Report, WO-GTR-82b. U.S. Department of Agriculture, Forest Service, Washington, DC, $64 \mathrm{p}$

Page-Dumroese DS, Abbott AM, Curran MP, Jurgensen MF (2012) Validating visual disturbance types and classes used for forest soil monitoring protocols, General Technical Report, RMRS-GTR-267. U.S. Department of Agriculture, Forest Service, Rocky Mountain Research Station, Fort Collins, $17 \mathrm{p}$

Pellant M, Shaver P, Pyke DA, Herrick JE (2005) Interpreting indicators of rangeland health, ver. 4, Technical reference, 1734-6. U.S. Department of the Interior, Bureau of Land Management, National Science and Technology Center, Denver, $122 \mathrm{p}$

Perry CH, Amacher MC (2009) Forest soils. In: Smith WB, Miles PD, Perry $\mathrm{CH}$, Pugh SA (Technical coordinators) Forest resources of the United States, 2007. General Technical Report, WO-GTR-78. U.S. Department of Agriculture, Forest Service, Washington Office, Washington, DC, pp 42-44

Perry CH, Amacher MC (2012) Chapter 9: Patterns of soil calcium and aluminum across the conterminous United States. In: Potter KM, Conkling BL (eds) Forest health monitoring: 2008 national technical report, General Technical Report SRS-GTR-158. U.S. Department of Agriculture, Forest Service, Southern Research Station, Asheville, pp 119-130

Ponder F Jr, Fleming RL, Berch S et al (2012) Effects of organic matter removal, soil compaction and vegetation control on tenth year biomass and foliar nutrition: LTSP continent-wide comparisons. For Ecol Manag 278:35-54

Powers RF, Alban DH, Miller RE et al (1990) Sustaining productivity of north American forests: problems and prospects. In: Gessel SP, Lacate DS, Weetman GF, Powers RF (eds) Sustained productivity of forest soils, proceedings of the seventh North American forest soils conference. University of British Columbia Faculty of Forestry, Vancouver, pp 49-79

Ramcharan A, Hengl T, Nauman T et al (2018) Soil property and class maps of the conterminous US at 100-meter spatial resolution based on a compilation of national soil point observations and machine learning. Soil Sci Soc Am J 82(1):186-201

Reed MS, Buenemann M, Atlhopheng J et al (2011) Cross-scale monitoring and assessment of land degradation and sustainable land management: a methodological framework for knowledge management. Land Degrad Dev 22:261-271

Reeves D, Coleman M, Page-Dumroese D (2013) Evidence supporting the need for a common soil monitoring protocol. J Ecosyst Manage 14(2): $1-16$

Riemann R, Wilson BT, Lister A, Parks S (2010) An effective assessment protocol for continuous geospatial datasets of forest characteristics using USFS Forest Inventory and Analysis (FIA) data. Remote Sens Environ 114:2337-2352

Ritz K, McNicol JW, Nunan N et al (2004) Spatial structure in soil chemical and microbiological properties in an upland grassland. FEMS Microbiol Ecol 49(2):191-205

Schoeneberger PJ, Wysocki DA, Benham EC, Soil Survey Staff (2012) Field book for describing and sampling soils, version 3.0. Natural Resources Conservation Service, National Soil Survey Center, Lincoln, $300 \mathrm{p}$

Shi X, Long R, Dekett R, Philippe J (2009) Integrating different types of knowledge for digital soil mapping. Soil Sci Soc Am J 73:1682-1692

Smith JE, Heath LS (2002) A model of forest floor carbon mass for the United States forest types, Research paper NE-722. U.S. Department of Agriculture, Forest Service, Northeastern Research Station, Newtown Square, $37 \mathrm{p}$

Soil Science Division Staff (2017) Soil survey manual. In: Ditzler C, Scheffe K, Monger HC (eds) USDA handbook 18. Government Printing Office, Washington, DC

Soil Survey Staff (2017) Web soil survey. U.S. Department of Agriculture, Natural Resources Conservation Service Washington, DC. Available at https://websoilsurvey.sc.egov.usda.gov/App/ HomePage.htm. Accessed 6 Mar 2019

U.S. Environmental Protection Agency [US EPA] (2017) Land use, land-use change, and forestry. In: Inventory of U.S. greenhouse gas emissions and sinks. EPA 430-P-17-001. Chapter 6

USDA Natural Resources Conservation System [USDA NRCS] (2012) Ecological Site Information System (ESIS): ecological site descriptions. https://esis.sc.egov.usda.gov/About.asp. Accessed 6 Mar 2019

USDA Natural Resources Conservation System [USDA NRCS] (n.d.) Ecological site information system (ESIS). https://esis.sc.egov.usda. gov/. Accessed 6 Mar 2019

Van Kley JE, Turner RL, Smith LS, Evans RE (2007) Ecological classification system for the national forests and adjacent areas of the west gulf coastal plain: second approximation. The Nature Conservancy and Stephen F. Austin State University, Nacogdoches, 379 p

Vogt JV, Safriel U, Von Maltitz G et al (2011) Monitoring and assessment of land degradation and desertification: towards new conceptual and integrated approaches. Land Degrad Dev 22(2): $150-165$

Wilson B, Tyler R, Woodall CW, Griffith DM (2013) Imputing forest carbon stock estimates from inventory plots to a nationally continuous coverage. Carbon Balance Manag 8(1):1-15 
Winthers E, Fallon D, Haglund J et al (2005) Terrestrial ecological uni inventory technical guide. U.S. Department of Agriculture, Forest Service, Washington Office, Ecosystem Management Coordination Staff, Washington, DC, $245 \mathrm{p}$
Woodall CW, Amacher MC, Bechtold WA et al (2011) Status and future of the forest health indicators program of the USA. Environ Monit Assess 177:419-436

Open Access This chapter is licensed under the terms of the Creative Commons Attribution 4.0 International License (http://creativecommons. org/licenses/by/4.0/), which permits use, sharing, adaptation, distribution and reproduction in any medium or format, as long as you give appropriate credit to the original author(s) and the source, provide a link to the Creative Commons license and indicate if changes were made.

The images or other third party material in this chapter are included in the chapter's Creative Commons license, unless indicated otherwise in a credit line to the material. If material is not included in the chapter's Creative Commons license and your intended use is not permitted by statutory regulation or exceeds the permitted use, you will need to obtain permission directly from the copyright holder. 